\title{
Does Preferential Trade Benefit Poor Countries? A General Equilibrium Assessment with Nonhomothetic Preferences *
}

\author{
Joachim Stibora ${ }^{\dagger}$ and Albert de Vaal ${ }^{\ddagger}$
}

September 14, 2006

\begin{abstract}
We study the effects of preferential trade agreements (PTA) in a model where income matters for consumption patterns. We develop a three-country Ricardian trade model in which goods are ranked according to priority and where economies differ in their income level. The poorest (richest) country has a comparative advantage in the production of lowest-ranked (highest-ranked) goods, specializing in goods with low (high) income elasticities in demand. The medium rich country specializes in the production of the intermediate-ranked commodities. We find that being a nonmember of a PTA leads to a terms of trade deterioration for a poor country, and a terms of trade improvement for the high-income country. Becoming a member of a PTA also does not guarantee welfare gains for the low income country, unless it is so poor that it cannot import the higher-ranked goods that the rich country produces.
\end{abstract}

Keywords: Ricardian trade model; asymmetric demand complementarities; Customs Union; income distribution.

JEL classification: F1

${ }^{*}$ We would like to thank Willy Spanjers, Peter Skott as well as participants of seminars at Kingston University, the Radboud University Nijmegen, the MWIEG Fall 2005 meeting in Lawrence, Kansas, the 2006 DEGIT XI workshop in Jerusalem, and the 2006 ETSG meeting in Vienna for their useful comments and suggestions. Finally, we thank Marcia Schafgans for her perceptive comments and moral support. All remaining errors are, of course, ours.

${ }^{\dagger}$ Faculty of Social Sciences, School of Economics, Kingston University, Kingston upon Thames, KT1 2EE, UK. Email:j.stibora@kingston.ac.uk

${ }^{\ddagger}$ Nijmegen School of Management, Department of Economics, Radboud University Nijmegen, The Netherlands. Email: a.devaal@fm.ru.nl. 


\section{Introduction}

In May 2004, eight new countries from central Europe (Estonia, Latvia, Lithuania, Poland, Czech Republic, Slovakia, Hungary, and Slovenia) have joined the European Union (EU), along with the Mediterranean islands of Cyprus and Malta. Bulgaria and Romania are expected to become full members on January 1st, 2007. These countries have a significantly lower per capita income and are also much more specialized in agriculture than the preaccession EU-15 average (see Baldwin and Wyplosz, 2003). This exemplifies the growing trend of regional integration between countries which differ significantly in their level of economic development. As has been reported by World Trade Organization (WTO, 2002), there is a growing trend towards preferential trade agreements (PTAs) between countries of substantially different income levels. ${ }^{1}$ Another prominent example is the North American Free Trade Agreement (Nafta), which includes the United States of America, Canada and Mexico.

The theoretical connection between the level of per capita income and preferential trade has not received adequate attention. In particular, the literature on PTAs has ignored the fact that different levels of development may imply different consumption patterns, as it focuses on comparative advantage as the main difference between countries, while assuming homothetic preferences. Though this is in keeping with common practice in international trade theory, we argue that in a world with persistent income differences between countries the impact of nonhomothetic preferences on trade patterns and welfare should not be ignored. ${ }^{2}$ Specifically, the similarity in consumption patterns implied by homothetic preferences is at odds with a number of stylized facts. First, many new, sophisticated products are developed in countries with high per capita incomes, created by entrepreneurs in response to perceived demand. Individuals in countries with lower per capita income tend to buy relatively unsophisticated products. Recent evidence for this is provided by Schott

\footnotetext{
${ }^{1}$ Of the 11 free trade areas that came into force between January 1, 2005 and June 15, 2006, 6 involved a commitment between developed and developing countries (www.wto.org/english/tratop_e/region_e/ region_e/eif_e.xls). The collapse of the multilateral trade Doha Round negotiations is expected to give further impetus to this phenomenon.

${ }^{2}$ The absence of studies relaxing the homotheticity assumption on demand can be understood in light of the fact that the first wave of PTAs in the 1950s almost exclusively involved countries with similar per capita incomes and that effective arrangements were restricted to Western Europe. Assuming homothetic preferences is then a natural choice in the theoretical literature, which indeed has been the case without exception (see Baldwin and Venables (1995), Bhagwati and Panagariya (1996a, 1996b), and Panagariya (2000) for an overview of the literature). A complicating factor has also been that until recently the possibility of relaxing the homotheticity assumption on demand rendered the analysis difficult, if not intractable (see for example Wilson, 1980).
} 
(2001). ${ }^{3}$ Second, sophisticated goods are originally developed and produced in developed countries and only at a later point in their cycle consumed in less developed countries (Vernon, 1966). Third, the volume of trade will be higher between countries with similar per capita income (Burenstam Linder, 1961).

The present paper develops a model for analyzing PTAs that assigns a central role to income differences between countries. The model builds on Matsuyama (2000), where nonhomothetic preferences are incorporated in a two country Ricardian trade model with a continuum of goods. We extend his framework and use it to gain insight into the issue of preferential trade arrangements between countries with different income levels. We rank countries such that the poorest country has a comparative advantage in the production of the lower-ranked goods, the richest country has a comparative advantage in the production of the highest-ranked goods, and the medium rich country has a comparative advantage in the production of intermediate-ranked goods. We assume that goods are indivisible and order them according to priority in consumption. The lowest-indexed goods have the highest priority in consumption, whereas the highest-indexed goods have the lowest priority in consumption. This paves the way for nonhomothetic preferences since poor households are not able to consume the same consumption basket as rich households. All households consume the lower-indexed, high-priority, goods, and when real income increases add higher-indexed, low-priority, goods to their consumption baskets, instead of buying more of the goods they already consumed. The higher-indexed, low-priority, goods are therefore only affordable by households with sufficiently high income levels. This implies that the poor (rich) country produces goods with low (high) income elasticities in demand and the medium rich country specializes in goods with intermediate income elasticities in demand. Assuming that goods are indivisible in consumption is a simple and tractable way to include nonhomothetic preferences in general equilibrium analyses, see e.g. Murphy et al. (1989), Krishna and Yavas (2005), and Bertola et al. (2006).

The significant contribution of analyzing PTAs within our framework is that it shows that the income level of a country plays an important role in assessing the impact of PTA formation. This holds when a country engages in a PTA itself, but also when it is left outside of a PTA. For a poor nonmember country, a PTA agreement typically implies a terms of trade deterioration, while for a rich nonmember country it implies a terms of trade improvement. Similarly, while nonmember countries by and large experience a deterioration of welfare following a PTA agreement, this is not so for a rich nonmember country. Whereas the nonmember country in general suffers from PTA members' expenditure switching, the rich country finds compensation in the way the real income gains of the PTA members are

\footnotetext{
${ }^{3}$ See also Deaton and Muellbauer (1980), Hunter and Markusen (1987) and Hunter (1991).
} 
spent. These accrue to the higher-ranked goods the rich country produces. Being a PTA member is no guarantee for welfare improvements. Only countries that are too poor to import the whole range of world products can be assured of welfare gains when opening up their borders preferentially. For the other countries we find that it depends to a large extent on how comparative advantages differ across the world. ${ }^{4}$ Furthermore, we show that it is not only the income differences per se that matter, but also the extent of these income differences. While being a low-income country leads to different inferences regarding the costs and benefits of PTA formation than being a medium- or high- income country, it also holds that these results depend highly on whether or not the low-income country is partly insulated from world trade. In fact, our analysis shows that very poor countries have most to gain by joining a preferential trade agreement with a rich counterpart.

The reason for these novel results is the inclusion of nonhomothetic preferences, giving rise to asymmetric demand complementarities (also called Hicks-Allen complements). As the price of lower-indexed goods falls, due to lower tariffs say, the resulting real income gain induces households to expand their consumption baskets by adding higher-indexed goods of lower priority. If, however, the price of higher-indexed goods falls, the demand for the lower-indexed, high priority, goods remains unaffected. Households do not respond to price changes of higher indexed goods by increasing consumption of lower-ranked goods. The demand complementarities are therefore asymmetric. The income effect of price changes renders higher-indexed goods complements to lower-indexed goods, but not the other way around. $^{5}$

Our paper fits in the growing literature on modelling nonhomothetic preferences, see Bertola et al. (2006, Chapter 11) for an overview. In the realm of trade and trade policy, noticeable contributions are Matsuyama (2000), Krishna and Yavas (2005), Mitra and Trindade (2006) and Stibora and de Vaal (2006). None of these papers, nor any other paper that we know of, links nonhomothetic preferences to the analysis of PTA formation.

Naturally, our paper also relates to the vast literature on PTA formation. The closest relation is to Appleyard, Conway and Field (1989) and the twin paper Conway, Appleyard and Field (1989), as they also consider PTA formation in a Ricardian trade model with a continuum of goods. Their model clearly differs with respect to the demand side, however. Both of their papers construct a similar model to ours but assume preferences to be Cobb-

\footnotetext{
${ }^{4}$ Bhagwati and Panagariya (1996, Chapter 1) suggest that the formation of PTA among unequal partners could be to the detriment of the less developed partner country. They do not provide a formal analysis for this claim.

${ }^{5}$ The definition of complementarity used here differs from the one given by Pareto and Edgeworth. In their view complementary goods are such that benefits are larger when goods are consumed together rather than separately (see Hicks and Allen, 1934).
} 
Douglas over a fixed range of goods. This implies that each household spends a constant expenditure share on each good regardless of the level of income. Consequently, in their models income differences - within and across countries - do not matter for the aggregate variables. By including nonhomothetic preferences, we take these issues into account, making it possible to analyze PTAs between countries that differ in their stage of economic development.

We proceed with the paper as follows. In Section 2, we extend Matsuyama's (2000) framework to allow for an analysis of the consequences of PTAs. In particular, we will include a third country, while we also incorporate import tariffs on initial trade flows. We specify initial trade equilibrium and discuss how the endogenous variables depend on the income distribution. In Section 3 we discuss two equilibrium configurations that may result. Depending on the level of income of the poor country, the equilibrium trade pattern can be either symmetric or asymmetric. This section provides also a more detailed comparison to the standard literature. In Section 4, we examine and explain how the inclusion of nonhomothetic preferences affects the general equilibrium effects of (unilateral) tariff reductions. In Section 5 and 6 we analyze the effects of various formations of PTAs. Section 5 discusses the effects of PTAs on specialization and the terms of trade of member and nonmember countries, while Section 6 discusses the concomitant welfare effects. Section 7 elaborates on which type of integration is more welfare enhancing for individual countries. It determines the welfare effects of unilateral and multilateral trade liberalization and compares these with the welfare effects of PTA formation. Section 8, finally, concludes.

\section{The Model}

We consider three countries, countries 1,2 , and 3 . In each country there exists a continuum of competitive industries, indexed by $z \in[0, \infty)$, each producing a homogeneous good also indexed by $z$, using labor only. For good $z$, let $a_{j}(z)$ be the unit labor requirement in country $j(j=1,2,3)$. We follow Appleyard, Conway and Field (1989) (hereafter: ACF) and make the following assumptions on technology:

Assumption $1 \frac{a_{i}(z)}{a_{1}(z)} \equiv A_{i}(z) \quad$ with $-\frac{z}{A_{i}} \frac{\partial A_{i}}{\partial z} \equiv \zeta_{i}>0 \quad$ for $i=2,3$ and all $z$.

Assumption $2 \zeta_{2}<\zeta_{3}$ for all $z$.

Assumption 1 is standard and requires that $A_{i}(i=2,3)$ is smooth, continuous, and strictly decreasing in $z \in[0, \infty)$. It ensures that commodities can be ranked in order of 
diminishing comparative advantage of country 1 relative to both country 2 and 3. Assumption 2 implies that $A_{3}(z)$ is relatively steeper than $A_{2}(z)$ so that $A_{3}(z) / A_{2}(z)$ is strictly decreasing in $z$. Assumption 2 ensures that country 3 has an increasing comparative advantage relative to country 2 for higher $z$.

We start from a situation in which trade flows are distorted by tariffs. Let $\tau_{j k}$ be one plus the ad valorem tariff in country $j$ on any of the commodities $z$ when it is produced in country $k$ (i.e. $\tau_{j k}=1+t_{j k}, t_{j k}>0$ for $j \neq k$ and for all $z$ ). Then, under perfect competition, given wages and tariffs, a country exports good $z$ when it can produce that good at the lowest cost. Let the relative wages be $\omega_{i}=w_{1} / w_{i}$ for $i=2,3$. It follows that there will be six equilibrium borderline goods $z_{k}$ for $k=1, . ., 6$ which demarcate for each country the range of own production, range of exports, and the range of non-traded goods. For given wages and tariffs, these borderline goods are represented by equalities in (1)-(6) (see ACF (1989), p.151).

- country 1 will export to country 2 if and only if $\tau_{21} w_{1} a_{1} \leqq w_{2} a_{2}$ and $\tau_{21} w_{1} a_{1} \leqq$ $\tau_{23} w_{3} a_{3}$ with borderline good $z_{1}$ determined by

$$
\tau_{21} \omega_{2}=a_{2}\left(z_{1}\right) / a_{1}\left(z_{1}\right)
$$

- country 1 will export to country 3 iff $\tau_{31} w_{1} a_{1} \leqq \tau_{32} w_{2} a_{2}$ and $\tau_{31} w_{1} a_{1} \leqq w_{3} a_{3}$ with borderline good $z_{2}$ determined by

$$
\tau_{31} \omega_{2}=\tau_{32} a_{2}\left(z_{2}\right) / a_{1}\left(z_{2}\right)
$$

- country 2 will export to country 1 iff $\tau_{12} w_{2} a_{2} \leqq w_{1} a_{1}$ and $\tau_{12} w_{2} a_{2} \leqq \tau_{13} w_{3} a_{3}$ with borderline good $z_{3}$ determined by

$$
\omega_{2}=\tau_{12} a_{2}\left(z_{3}\right) / a_{1}\left(z_{3}\right)
$$

- country 2 will export to country 3 iff $\tau_{32} w_{2} a_{2} \leqq w_{3} a_{3}$ and $\tau_{32} w_{2} a_{2} \leqq \tau_{31} w_{1} a_{1}$ with borderline good $z_{4}$ determined by

$$
\omega_{2} / \omega_{3}=\tau_{32} a_{2}\left(z_{4}\right) / a_{3}\left(z_{4}\right)
$$

- country 3 will export to country 1 iff $\tau_{13} w_{3} a_{3} \leqq \tau_{12} w_{2} a_{2}$ and $\tau_{13} w_{3} a_{3} \leqq w_{1} a_{1}$ with borderline good $z_{5}$ determined by

$$
\omega_{3} / \omega_{2}=a_{3}\left(z_{5}\right) \tau_{13} / a_{2}\left(z_{5}\right) \tau_{12}
$$


- country 3 will export to country 2 iff $\tau_{23} w_{3} a_{3} \leqq w_{2} a_{2}$ and $\tau_{23} w_{3} a_{3} \leqq \tau_{21} w_{1} a_{1}$ with borderline good $z_{6}$ determined by

$$
\omega_{3} / \omega_{2}=\tau_{23} a_{3}\left(z_{6}\right) / a_{2}\left(z_{6}\right) .
$$

Figure 1 gives a graphical representation of the trade patterns in terms of the borderline goods. Country 1 produces all $z \in\left[0, z_{3}\right)$, of which $\left[z_{2}, z_{3}\right]$ are not traded and $\left[0, z_{1}\right]$ and $\left[0, z_{2}\right]$ are exported respectively to country 2 and 3 . Country 2 produces all $z \in\left[z_{1}, z_{6}\right)$, of which $\left[z_{1}, z_{2}\right]$ and $\left[z_{5}, z_{6}\right]$ are not traded and $\left[z_{3}, z_{5}\right]$ and $\left[z_{2}, z_{4}\right]$ are respectively exported to country 1 and 3 . Country 3 , finally, produces all $z \in\left[z_{4}, u_{3}\right]$, of which $\left[z_{4}, z_{5}\right]$ are not traded, while $\left[z_{5}, u_{1}\right]$ and $\left[z_{6}, u_{2}\right]$ are respectively exported to country 1 and 2 . Here $u_{j}$ denotes the highest-indexed good $z$ a household from country $j, j=1,2,3$, consumes. The resulting trade pattern satisfies $z_{1}<z_{2}<z_{3}<z_{4}<z_{5}<z_{6}$ as long as (i) directly exporting good $z$ costs less than exporting the same good via a third country and (ii) tariff rates do not differ too much between countries. For example, given assumptions 1 and 2 and conditions (5) and (6), $z_{5}<z_{6}$ holds unless $\tau_{13}>\tau_{12} \tau_{23}$ that is, if the direct tariff country 1 pays on imports from country 3 is larger than the tariffs country 1 pays on imports from country 3 when good $z$ is imported via country 2 . The exception is $z_{3}<z_{4}$ where $z_{4}<z_{3}$ is also possible. We exclude this possibility and assume $z_{3}<z_{4}$ for the rest of the analysis. ${ }^{6}$ As we will argue later, the trade patterns depicted only hold when households in all three countries are rich enough to consume the higher-indexed goods country 3 produces, in contrast to ACF.

\section{(insert Figure 1 about here)}

As country 1 exports all goods of the lower spectrum of commodities, country 3 the higherranked commodities, and country 2 the middle-ranked goods, local prices are determined by

$$
p_{k}(z)=\min _{j}\left[\tau_{k j} w_{j} a_{j}(z)\right]
$$

Even if traded, the local price of good $z$ does not need to be identical.

On the demand side, we assume there are $N_{j}$ households in country $j$. In line with Matsuyama (2000) and Stibora and de Vaal (2006), we assume that the income distribution is nondegenerate and brought about by tariff rebates and by differences in skills reflected in differences in effective labor supply. We let $F_{j}\left(h_{j}\right)$ denote the distribution of effective (skill

\footnotetext{
${ }^{6}$ If $z_{4}<z_{3}$ this would create an additional range of nontraded goods for country 2 , but would otherwise not change any of the main results.
} 
based) labor supply across households in country $j$. The total labor supply thus equals $L_{j}=N_{j} \int_{0}^{\infty} h_{j} d F_{j}\left(h_{j}\right)$ in each country.

The consumption set of a household includes a continuum of $z \in[0, \infty)$. All households have the same preferences and maximize $V=\int_{0}^{\infty} b(z) x(z) d z$ subject to the budget constraint $\int_{0}^{\infty} p(z) x(z) d z \leq I$. In these expressions, $x(z)=\{0,1\}$ denotes the 'quantity' a household consumes and $b(z)>0$ the utility it receives from consuming good $z$. Thus, following Murphy, Shleifer, and Vishny (1989), goods come in discrete units and a household's desire to consume good $z$ is satiated after the consumption of one unit. This has the strong implication that, in contrast to standard analysis, an increase in utility is reflected in the consumption of an increased number of goods rather than in the consumption of higher quantities of a fixed number of goods. As such, wealthier households consume all the goods consumed by poor households, plus some. Moreover, the linearity of the utility function in $b$ implies the absence of any substitution effects and that only income effects are important for our results.

The order in which each household purchases goods is assumed to be the same as the ordering of goods due to comparative advantage. Hence, we assume that households consider lower-indexed goods to be of higher priority. These are purchased first and when income increases households add goods with lower priority to their consumption baskets. This requires that the order of utility per unit price is strictly decreasing in $z$, which is made explicit by assumption 3 .

Assumption $3 \frac{b(z)}{p_{k}(z)}=\frac{b(z)}{\min _{j}\left[\tau_{k j} w_{j} a_{j}(z)\right]}$ is strictly decreasing in $z$, for given $w_{j}$ and $\tau_{k j}$.

Assumption 3 implies that the marginal utility of income is decreasing in $z$.

The combination of assumptions 1, 2, and 3 implies that (i) country 1 has a comparative advantage in the production of lower-ranked goods that poor households purchase: (ii) country 3 has a comparative advantage in the production of higher-ranked goods that rich households purchase; (iii) country 2 has a comparative advantage in the production of intermediate-ranked goods that are purchased by households richer than those purchasing goods from country 1 but poorer than those purchasing goods from country 3 .

We now define

$$
E_{j}(z) \equiv \int_{0}^{z} p_{j}(s) d s=\int_{0}^{z} \min \left\{\tau_{j k} w_{k} a_{k}(z)\right\} d s
$$

as the minimum level of income that allows a household from country $j$ to consume good $z$. As the range of goods consumed will typically include imported goods, tariff revenues also affect the income distribution. We assume that the tariff revenue each household generates 
by purchasing imported goods, if any, is collected by the government and redistributed across households in a lump-sum fashion. Let us denote these tariff rebates in country $j$ by $T R_{j}$ and let us also assume that households take those rebates from the government as given. The highest-indexed commodity a household in country $j$ with income $w_{j} h_{j}+T R_{j}$ is able to consume, $u_{j}\left(h_{j}\right)$, is determined by the requirement that

$$
E_{j}\left[u_{j}\left(h_{j}\right)\right]=w_{j} h_{j}+T R_{j}
$$

for $j=1,2,3$. The utility level a household in country $j$ attains when consuming $u_{j}\left(h_{j}\right)$ is $V_{j}\left(h_{j}\right)=B\left(u_{j}\left(h_{j}\right)\right)$ where $B(z) \equiv \int_{0}^{z} b(s) d s . V_{j}\left(h_{j}\right)$ maps one-to-one into $u_{j}\left(h_{j}\right)$, the highest-indexed good it consumes. We therefore use the latter as a measure of utility (see Matsuyama (2000)).

Good $z$ is purchased by households only if their income is not lower than $E_{j}(z)$, or, equivalently, if their skill is such that $w_{j} h_{j}+T R_{j}$ exceeds $E_{j}(z)$. The fraction of households with income (skills) in excess of $E_{j}(z)$, thus with $w_{j} h_{j}>E_{j}(z)-T R_{j}$, is given by $1-$ $F_{j}\left(\left[E(z)-T R_{j}\right] / w_{j}\right)$. Aggregate demand for good $z$ is the number of households from the three countries whose income is equal or greater than $E_{j}(z)$, with demand from country $j$ given by

$$
Q_{j}(z)=N_{j}\left[1-F_{j}\left(\frac{E(z)-T R_{j}}{w_{j}}\right)\right] \quad \text { for } j=1,2,3 .
$$

In contrast to the standard literature, equation (9) indicates that total demand for good $z$ does not depend on aggregate income but on the number of households that have a sufficient level of income (skill) to consume it.

In the presence of tariffs, country 1 produces only goods in $\left[0, z_{3}\right)$, of which $\left[0, z_{1}\right]$ are exported to country 2 and of which $\left[0, z_{2}\right]$ are exported to country 3 . Consequently, labor market equilibrium in country 1 has to satisfy:

$$
\begin{aligned}
L_{1} & =N_{1} \int_{0}^{\infty} h_{1} d F_{1}\left(h_{1}\right) \\
& =\int_{0}^{z_{3}} a_{1}(z) Q_{1}(z) d z+\int_{0}^{z_{2}} a_{1}(z) Q_{3}(z) d z+\int_{0}^{z_{1}} a_{1}(z) Q_{2}(z) d z .
\end{aligned}
$$

The left hand side of (10) represents country 1's effective labor supply. The right hand side is the derived demand for country 1 labor. Combining (10) and (9), and using (7), country 1 's labor market equilibrium can be expressed as (see Appendix A.1 for details)

$$
\begin{aligned}
w_{1} L_{1}= & N_{1} \int_{0}^{\infty} \min \left[w_{1} h_{1}+T R_{1}, E_{1}\left(z_{3}\right)\right] d F_{1}\left(h_{1}\right) \\
& +\frac{N_{2}}{\tau_{21}} \int_{0}^{\infty} \min \left[w_{2} h_{2}+T R_{2}, E_{2}\left(z_{1}\right)\right] d F_{2}\left(h_{2}\right) \\
& +\frac{N_{3}}{\tau_{31}} \int_{0}^{\infty} \min \left[w_{3} h_{3}+T R_{3}, E_{3}\left(z_{2}\right)\right] d F_{3}\left(h_{3}\right),
\end{aligned}
$$


with $E_{2}\left(z_{1}\right)=\tau_{21} \int_{0}^{z_{1}} w_{1} a_{1}(s) d s, E_{3}\left(z_{2}\right)=\tau_{31} \int_{0}^{z_{2}} w_{1} a_{1}(s) d s$, and $E_{1}\left(z_{3}\right)=\int_{0}^{z_{3}} w_{1} a_{1}(s) d s$. Equation (11) defines national income for country 1, which has to be equal to the total spending on goods produced in that country (including tariffs). Total spending, in turn, is the sum of country 1's expenditure on its own goods, and the other countries' expenditure on country 1 goods. We note that country 1's tariff rebate as a result of imports, $T R_{1}$, is only positive if the income of (some of the) households in country 1 exceeds $E_{1}\left(z_{3}\right)$, otherwise tariff revenues are zero. To raise tariff revenues, country 1 should therefore at least be rich enough to import goods from country 2. By contrast, the tariff rebates for country 2 and country $3\left(T R_{2}\right.$ and $\left.T R_{3}\right)$ are always positive, since households from those countries always import the lower-indexed goods that are produced in country 1.

Similar reasoning applies to the labor market equilibrium conditions for country 2 and 3 , which we derive in Appendix A.2. In line with standard practice in trade theory literature, we replace the three labor market equilibrium conditions by the equivalent statement that in equilibrium trade has to be balanced. For the trade balance condition of country 1, we obtain

$$
\begin{aligned}
& \frac{N_{2}}{\tau_{21}} \int_{0}^{\infty} \min \left[w_{2} h_{2}+T R_{2}, E_{2}\left(z_{1}\right)\right] d F_{2}\left(h_{2}\right)+\frac{N_{3}}{\tau_{31}} \int_{0}^{\infty} \min \left[w_{3} h_{3}+T R_{3}, E_{3}\left(z_{2}\right)\right] d F_{3}\left(h_{3}\right) \\
& =\int_{0}^{\infty}\left\{\frac{N_{1}}{\tau_{12}} \min \left[w_{1} h_{1}+T R_{1}-E_{1}\left(z_{3}\right), E_{1}\left(z_{5}\right)-E_{1}\left(z_{3}\right)\right]\right. \\
& \left.\quad+\frac{N_{1}}{\tau_{13}} \max \left[w_{1} h_{1}+T R_{1}-E_{1}\left(z_{5}\right), 0\right]\right\} d F_{1}\left(h_{1}\right)
\end{aligned}
$$

and for country 2 :

$$
\begin{aligned}
& \int_{0}^{\infty}\left\{\frac{N_{2}}{\tau_{21}} \min \left[w_{2} h_{2}+T R_{2}, E_{2}\left(z_{1}\right)\right]+\frac{N_{2}}{\tau_{23}} \max \left[w_{2} h_{2}+T R_{2}-E_{2}\left(z_{6}\right), 0\right]\right\} d F_{2}\left(h_{2}\right) \\
& =\frac{N_{1}}{\tau_{12}} \int_{0}^{\infty} \min \left[w_{1} h_{1}+T R_{1}-E_{1}\left(z_{3}\right), E_{1}\left(z_{5}\right)-E_{1}\left(z_{3}\right)\right] d F_{1}\left(h_{1}\right) \\
& +\frac{N_{3}}{\tau_{32}} \int_{0}^{\infty} \min \left[w_{3} h_{3}+T R_{3}-E_{3}\left(z_{2}\right), E_{3}\left(z_{4}\right)-E_{3}\left(z_{2}\right)\right] d F_{3}\left(h_{3}\right),
\end{aligned}
$$

where $E_{1}\left(z_{5}\right)-E_{1}\left(z_{3}\right)=\tau_{12} \int_{z_{3}}^{z_{5}} w_{2} a_{2}(s) d s$ and $E_{3}\left(z_{4}\right)-E_{3}\left(z_{2}\right)=\tau_{32} \int_{z_{2}}^{z_{4}} w_{2} a_{2}(s) d s$. Note that both (12) and (13) give a representation of the demand side only. The first row in (12) $[(13)]$ represents the value of country 1's [2's] exports, which, in equilibrium, has to equal its value of imports due to the static nature of the model.

The six equations that determine efficient production, (1)-(6), together with the balanced trade conditions (12)-(13) and the three budget conditions, given by (8), define a system of 11 equations which jointly determine the equilibrium values of the marginal goods $z_{1}-z_{6}$, the relative wage rates $\omega_{i}\left(\equiv w_{1} / w_{i}\right)$ for $i=2,3$, and the utility levels $u_{j}$ for $j=1,2,3$. As is apparent from (12) and (13), the skill distribution of $h_{j}$ and the 
distribution of $T R_{j}$ affect the endogenous variables. This is a direct result of incorporating nonhomothetic preferences. While the income of some households (in some countries) will be sufficient to buy the highest-indexed good, for other households income may only suffice to buy lower-indexed goods. This affects the precise form of the trade balance conditions as we show in the next section.

To facilitate us to focus on the relation between PTA formation and global income disparities we make two further assumptions: ${ }^{7}$

Assumption $4 h_{j}=1, j=1,2,3$.

Assumption $5 a_{2}(z) / a_{1}(z)<1$ and $a_{3}(z) / a_{2}(z)<1$ for all $z \in[0, \infty)$.

Assumption 4 states that households in country $j$ have identical skill levels. As such, assumption 4 eliminates income differences within countries but not necessarily across countries. This requires Assumption 5, which ensures that $\omega_{2}<1<\omega_{2} / \omega_{3}$. When combined with assumptions 1-3, it follows that country 1 (3) is the low-income (high-income) country, which specializes in lower-indexed (higher-indexed) goods with low (high) income elasticities in demand; and country 2 is the middle-income country, which specializes in the intermediate range of goods with intermediate income elasticities in demand. ${ }^{8}$

\section{Symmetric and Asymmetric Trade Equilibrium}

Given assumptions 1-3, the model always generates a unique equilibrium, but two equilibrium configurations turn out to be of special interest. The first equilibrium outcome holds when all households spend their last unit of income on goods produced in country 3 . The resulting trade pattern is characterized by two-way bilateral trade flows between any pair of countries. We refer to this equilibrium configuration as the symmetric trade equilibrium. The conditions for balanced trade become, in place of (12) and (13) (see Appendix B):

$$
N_{1}\left(1-\int_{0}^{z_{3}} a_{1}(s) d s\right)=N_{2} \int_{0}^{z_{1}} a_{1}(s) d s+N_{3} \int_{0}^{z_{2}} a_{1}(s) d s
$$

\footnotetext{
${ }^{7}$ Similar assumptions have been made by Flam and Helpman (1987) and Stokey (1991) in the context of simple North-South trade models with nonhomothetic preferences. Additionally, those authors assume that goods are ranked according to product quality and that goods are gross substitutes. However, they do not analyze the formation of PTAs.

${ }^{8}$ Violation of assumption 5 could imply that country 3 households become so poor that they are only able to consume goods from countries 1 and 2. All the high-indexed goods country 3 produces are then exported to the two richer countries. For obvious reasons, we do not pursue this parameter constellation.
} 
and

$$
N_{2}\left(1-\int_{z_{1}}^{z_{6}} a_{2}(s) d s\right)=N_{1} \int_{z_{3}}^{z_{5}} a_{2}(s) d s+N_{3} \int_{z_{2}}^{z_{4}} a_{2}(s) d s,
$$

where the left-hand-side in (14) [(15)] denotes the value of country 1's [country 2's] imports and the right-hand-side the corresponding value of exports. The highest-indexed good $u_{j}$ that is associated with the symmetric trade equilibrium is derived from (8) and is given by

$$
\begin{gathered}
\int_{0}^{z_{3}} a_{1}(s) d s+\int_{z_{3}}^{z_{5}} \frac{a_{2}(s)}{\omega_{2}} d s+\int_{z_{5}}^{u_{1}} \frac{a_{3}(s)}{\omega_{3}} d s=1 \\
\int_{0}^{z_{1}} a_{1}(s) d s+\int_{z_{1}}^{z_{6}} \frac{a_{2}(s)}{\omega_{2}} d s+\int_{z_{6}}^{u_{2}} \frac{a_{3}(s)}{\omega_{3}} d s=\frac{1}{\omega_{2}} \\
\int_{0}^{z_{2}} a_{1}(s) d s+\int_{z_{2}}^{z_{4}} \frac{a_{2}(s)}{\omega_{2}} d s+\int_{z_{4}}^{u_{3}} \frac{a_{3}(s)}{\omega_{3}} d s=\frac{1}{\omega_{3}} .
\end{gathered}
$$

The absence of any tariff terms in these budget constraints is due to the fact that households actually pay a tariff exclusive price as a result of the proportional tariff rebates. The symmetric trade equilibrium corresponds to the one illustrated in Figure 1.

The second equilibrium configuration we consider is when households from country 1 are not rich enough to consume goods produced in country 3. In this case households in country 1 spend their last unit of income on goods produced in country 2, while households in country 2 and 3 still spend their marginal income on goods produced in country 3 , that is, $w_{1}+T R_{1}-E_{1}\left(z_{3}\right)<E_{1}\left(z_{5}\right)-E_{1}\left(z_{3}\right)$. This equilibrium configuration also involves one-way bilateral trade flows and we will refer to this outcome as the asymmetric trade equilibrium. ${ }^{9}$ Country 1 does not import from country 3 and runs a trade surplus with country 3 , implying that country 2 has a bilateral trade surplus with country 1, and country 3 has a bilateral trade surplus with country 2. The conditions for balanced trade become:

$$
N_{1}\left(1-\int_{0}^{z_{3}} a_{1}(s) d s\right)=N_{2} \int_{0}^{z_{1}} a_{1}(s) d s+N_{3} \int_{0}^{z_{2}} a_{1}(s) d s
$$

and

$$
N_{2}\left(1-\int_{z_{1}}^{z_{6}} a_{2}(s) d s\right)=\omega_{2} N_{1}\left(1-\int_{0}^{z_{3}} a_{1}(s) d s\right)+N_{3} \int_{z_{2}}^{z_{4}} a_{2}(s) d s .
$$

As before, the left hand side of (19) [(20)] represents country 1's [country 2's] value of imports which equals their respective value of exports, the right hand side. The noteworthy difference with the symmetric trade equilibrium is the inclusion of $\omega_{2}$ in (20), to which we

\footnotetext{
${ }^{9}$ As such, our framework also provides an alternative, demand-side explanation for the asymmetries in bilateral trade flows Helpman et al. (2005) have recently drawn attention to. They claim that for about $10 \%$ of all country pairs trade is one-way only. Taking into account that nearly half of all country pairs do not trade with each other, this implies that roughly $20 \%$ of all bilateral trade flows is one-way.
} 
will come back below. Since $u_{1}<z_{5}$, the budget constraint of country 1 household, (16), changes into

$$
\int_{0}^{z_{3}} a_{1}(s) d s+\int_{z_{3}}^{u_{1}} \frac{a_{2}(s)}{\omega_{2}} d s=1
$$

while the budget constraints for country 2 and 3 remain (17) and (18), respectively. Consequently, the asymmetric equilibrium satisfies $z_{1}<\ldots<u_{1}<z_{5}<z_{6}<u_{2}<u_{3}$, making $z_{5}$ redundant in the analysis (and in Figure 1).

Many features of these two equilibrium configurations deserve emphasis. Let us concentrate on the most important ones. First, the assumed preferences in our set-up imply that goods are not gross substitutes, which is a fundamental difference with the standard literature on the formation of PTAs. If the price of lower-indexed goods declines, consumers do not substitute toward relatively cheaper goods but instead expand the consumption basket always toward higher-indexed goods, as a result of the higher purchasing power. On the other hand, if the price of higher-indexed good falls, consumers do not switch expenditures towards lower-ranked goods.

Second, direct income effects only affect the balanced trade conditions of the asymmetric trade equilibrium configuration and not those of the symmetric trade equilibrium configuration. To see this, consider the effects of an increase in the factor reward in country 2 , ceteris paribus. ${ }^{10}$ In the symmetric trade equilibrium, this raises the real income of country 2 households with respect to imported goods, which is completely spent on goods from country 3. Likewise, it diminishes the real income of country 1 and country 3 households - they face higher import prices for country 2 goods- which reduces spending on country 3 goods. With initially balanced trade, these spending effects exactly cancel out, leaving a net change in spending on goods from country 3 of zero. As a similar reasoning holds for changes in the factor rewards of the other countries, it follows that in the symmetric trade equilibrium direct real income effects do not affect the trade balance conditions, explaining the absence of $\omega_{i}, i=2,3$ in the trade balance condition. This is different for the asymmetric trade equilibrium configuration. Households in country 1 are then too poor to buy the higher-indexed goods from country 3 and the decline in their real incomes affects spending on country 2 goods instead. Since this is unmatched by any of the other spending effects the real income effects of country 2 and country 3 households still apply to country 3 goods - the net effect on spending on country 2 goods is negative and $\omega_{2}$ enters the balanced trade condition of country $2 .^{11}$

\footnotetext{
${ }^{10}$ Direct income effects due to tariff changes are absent since tariff rebates imply that consumers pay a tariff-exclusive price.

${ }^{11}$ Applying analogue reasoning to changes in the factor rewards of the other countries explains why $\omega_{2}$
} 
Third, the distinction between symmetric and asymmetric trade patterns arises endogenously in our model. The distinction itself is of course not new as several authors have used it to facilitate their analysis, see, for instance, Meade (1955), Mundell (1964), ACF, and Berglas (1979). The notable difference, however, is that in our framework the (a)symmetry in trade patterns is a general equilibrium outcome, rather than a structure that is being imposed. This novel aspect allows us to analyze the consequences of trade policy on trade and welfare in a multiregional setting in the presence of significant income effects in a tractable manner.

\section{Unilateral Tariff Policy among Heterogeneous Coun- tries}

To examine and explain how the inclusion of nonhomothetic preferences matters for the general equilibrium effects of tariff reductions, we first examine the effects of unilateral tariff reductions in a three country setting. For the purpose at hand we assume that assumptions 4 and 5 hold. To simplify calculations, we additionally assume that a country initially levies uniform tariff rates on all imports regardless of the source, i.e., $\tau_{j k}=\tau_{j k^{\prime}}$ for $j, k, k^{\prime}=1,2,3$ and $k \neq k^{\prime}$. This is in keeping with the "most favoured nation" (MFN) clause of the GATT Articles of Agreement. We contrast our results with those of ACF, as their analysis is the closest parallel to our work. ${ }^{12}$ They, however, assume that all households have identical and homothetic preferences over a fixed range of commodities, which can be represented by $V_{j}=\int_{0}^{1} \beta(z) \ln e_{j}(z) d z$, with real expenditure on good $z$ denoted by $e_{j}(z)$ and constant expenditure shares $\beta(z)>0$, which are uniform across all three countries, and $\int_{0}^{1} \beta(z) d z=$ 1. This assumption implies that each household spends the fraction $\theta\left(z_{i}\right)=\int_{0}^{z_{i}} \beta(z) d z$ of income on a subset of goods regardless of the level of income. The qualitative impact of tariff changes is summarized in Table 1, with mathematics relegated to Appendix C.

\section{(insert Table $1 a / b$ about here)}

From Table 1a, it is immediately apparent that in the present model a unilateral change of either country 1 or 2's tariff on imports from country $3\left(\tau_{13}\right.$ and $\left.\tau_{23}\right)$ does neither affect does not show up in the trade balance of country 1 and why $\omega_{3}$ does not show up in either of the two trade balance equations. The former is because none of the spending effects apply to country 1 goods. The latter is because changes in the factor reward of country 3 have no bearing on spending on country 2 goods.

${ }^{12}$ As the ACF framework does not allow for asymmetric spending patterns, the comparison is only relevant for the symmetric trade equilibrium. 
efficient production of country 1 nor its relative wage ratio with country $2, \omega_{2}$. Consider, for instance, the reduction in country 2 's tariff on imports from country $3\left(d \tau_{23}<0\right)$. This lowers the prices of those goods in country 2, but as consumers pay a tariff exclusive price (due to tariff rebates), there is no direct demand side effect on the trade balance. At initial factor prices, country 2 loses some industries to country 3 that were in direct competition $\left(z_{6}\right.$ falls). Since this competition effect also reduces country 2's range of nontraded goods, real income gains accrue for households from country 2 in terms of those goods only, to which they respond by adding higher-indexed goods produced in country 3 to their consumption basket, that is $d u_{2}>0$. In the absence of substitution effects, demand for country 1's produce is unaffected and no change in $\omega_{2}$ is required. The ensuing trade deficit for country 2 requires a deterioration in country 2's terms of trade with respect to country 3 (higher $\omega_{2} / \omega_{3}$ ) to restore equilibrium, implying a deterioration in country 1's terms of trade with respect to country 3 (lower $\left.\omega_{3}\right)$.

These results are in sharp contrast to the ones derived by ACF that are given in the lower panel of Table 1a for comparison. Considering the same reduction in $\tau_{23}$, country 3 's terms of trade with respect to country 2 and 1 improve (higher $\omega_{2} / \omega_{3}$ and lower $\omega_{3}$ ). In contrast to our model, however, country 1's terms of trade vis-à-vis country 2 have to change (higher $\omega_{2}$ ). The main reason is the presence of substitution effects in their framework. Lower prices of country 3's goods in country 2 induces households to substitute away from the relatively more expensive domestic and country 1 goods. The bilateral trade balance of country 3 with 2 moves into surplus and the bilateral trade balance of country 1 with 2 into deficit, requiring changes in the factor terms of trade to preserve balanced trade equilibrium.

The difference in demand structure has important implications for the analysis to follow. Comparing our results in Table 1a with those of ACF shows that our results are often determined by (i) the degree of comparative advantage a country has at a particular borderline good $z_{k}$ - represented by the parameters $\zeta_{2}>0$ and $\zeta \equiv \zeta_{3}-\zeta_{2}>0$, and (ii) the size of real income changes, which are decisively determined by the population size.

With regard to the degree of comparative advantage, consider, for example, a reduction in country 1's tariff on imports from country 2, that is, $d \tau_{12}<0$, ceteris paribus. At initial relative wages, a fall in $\tau_{12}$ reduces the price of country 2 goods in country 1 , and its range of imports from country 2 increases at the expense of (some) domestic firms (lower $z_{3}$ ) and of some firms from country 3 that directly compete with country 2 firms on country 1's market (higher $z_{5}$ ). The extent of comparative advantage at the borderline commodities is important as it determines how many industries are lost to other countries. If, for instance, $\zeta_{2}$ is low, country 1 has a weak comparative advantage compared to country 2 at 
$z_{3}$, implying a substantial loss of industries to country 2. A low $\zeta$, by contrast, implies that country 3's comparative advantage vis-à-vis country 2 is weak at $z_{5}$, enabling country 2 to take over a considerable number of country 3's export industries to country 1 . Of these competition effects, the reduction in $z_{3}$ increases the real income of country 1 households, while the increase in $z_{5}$ increases real income in country 2 and decreases real income in country 3 .

Confining ourselves to the symmetric trade equilibrium, all real income changes affect spending on country 3 goods only. For country 1 these effects therefore imply a loss of industries to country 2 , while it increases spending on goods from country $3, d u_{1}>0$. The competition effect explains why country 1's factor terms of trade with country 2 deteriorates irrespective of $\zeta_{2}$ and $\zeta$ (lower $\omega_{2}$ ); the spending effect helps to explain the deterioration of its factor terms of trade with country 3 . The weaker its comparative advantage at $z_{3}$, the higher the real income gains and the more spending on country 3 goods will expand. ${ }^{13}$ For the effects on country 3 the values $\zeta$ and $\zeta_{2}$ take are more important. Suppose that $\zeta_{2}$ is small, for a given positive value of $\zeta \equiv \zeta_{3}-\zeta_{2}$. This implies large real income gains for country 1 households, but hardly any competition effects between country 2 and country 3. The real income gains become effective in country 3 , and to restore equilibrium, country 3 's relative factor terms of trade have to improve (lower $\omega_{3}$ and, in the absence of strong competition effects, $\omega_{2} / \omega_{3}$ goes up). Suppose now that $\zeta_{2}$ is given, and that $\zeta$ is small but positive. The real income gains in country 1 are much smaller than before, so that the effects are dominated by the large competition effect on the borderline commodity of country 2 and 3. At initial factor prices, country 3's balance of trade turns into a deficit and country 3's factor terms of trade have to deteriorate to restore equilibrium (lower $\left.\omega_{2} / \omega_{3}\right)$.

To see the importance of the size of real income changes and thus the size of the population on the endogenous variables, let us consider the tariff reduction $d \tau_{31}<0$, ceteris paribus. This reduces the price of country 1's imports in country 3 and firms from country 1 gain in competitiveness with respect to firms from country 2 so that $z_{2}$ goes up. At initial factor prices, country 1 experiences a trade surplus, while for country 2 an equivalent deficit results. Country 1's terms of trade vis-a-vis country 2 has to improve (higher $\omega_{2}$ ) to restore equilibrium. This indirectly reduces $z_{2}$, but the direct effect overcomes the indirect effect and $z_{2}$ increases. Recall that the change in $\omega_{2}$ has no direct effect on country 3 's initial trade balance. However, it will affect all other borderline goods in addition to $z_{2}$. In particular, country 1's range of domestic production falls (lower $z_{3}$ ) and previously non-traded goods

\footnotetext{
${ }^{13}$ As shown in the appendix, the change in $d u_{1}$ for given relative wages is affected by both the change in $z_{3}$ and $z_{5}$. Assuming that country 1 imposes the same tariff on imports from country 2 and 3 in the original equilibrium, that is $\tau_{12}=\tau_{13}$, the latter effect cancels.
} 
are now imported from country 2. This increases country 1's real income and its imports from country 3 increases by $N_{1} a_{1}\left(z_{3}\right) z_{3}\left(1-1 / \tau_{12}\right)$. On the other hand, country 2 's range of production increases at the lower end (lower $z_{1}$ ) and households replace goods previously imported from country 1 with domestic goods that are now non-traded. Country 2's real income falls and so are its imports from country 3 to the extent of $N_{2} a_{1}\left(z_{1}\right) z_{1}\left(\tau_{21}-1\right)$. Assuming that $N_{1} a_{1}\left(z_{3}\right) z_{3}\left(1-1 / \tau_{12}\right)>N_{2} a_{1}\left(z_{1}\right) z_{1}\left(\tau_{21}-1\right)$, country 3 's trade balance turns into a surplus. The increase of $\omega_{2}$ also affects the upper range of the borderline goods $z_{k}$, for $k=4,5,6$. From the point of view of country 3, imports from country 2 increase (higher $z_{4}$ ), while exports to countries 2 and 1 decrease (higher $z_{5}$ and $z_{6}$ ). With imports increasing on net, country 3 's trade balance turns into a deficit. The improvement of $\omega_{2}$ for given $\omega_{3}$ has an ambiguous effect on country 3's trade balance and hence on the required change in $\omega_{3}$. For given positive $\zeta$, and letting $N_{1} a_{1}\left(z_{3}\right) z_{3}\left(1-1 / \tau_{12}\right)>N_{2} a_{1}\left(z_{1}\right) z_{1}\left(\tau_{21}-1\right)$, a small $\zeta_{2}$ implies that the real income effect dominates the competition effect and country 3 's trade balance turns into a surplus. As a consequence, $\omega_{3}$ has to fall for country 3's relative wage ratio with country 2 to improve (higher $\omega_{2} / \omega_{3}$ ). By contrast, for $\zeta_{2}$ positive and $\zeta$ small, the real income effect is negligible and the increase in imports dominate. Country 3's trade balance turns into a deficit and its terms of trade with country 1 have to deteriorate (higher $\left.\omega_{3}\right)$ relative to the higher $\omega_{2}$ to reduce the increase in country 3's imports. ${ }^{14}$

Some of the ambiguities are resolved when considering the asymmetric trade equilibrium. Recall that this equilibrium configuration implies that country 1 spends its last unit of income on goods produced in country 2 instead of country 3. Consequently, the real income gain due to, for example, lower $\tau_{12}$ becomes effective in country 2 and country 3 's trade balance turns unambiguously into a deficit, at initial factor prices (see Table 1b). Likewise, the same fall in $\tau_{31}$ that improves country 1's relative wage ratio with country 2 , ceteris paribus, increases country 1's imports from country 2 but reduces country 2's imports from country 3 , thereby generating a trade deficit for country 3 . To restore equilibrium country 3's relative wage ratio with country 2 has to deteriorate (lower $\omega_{2} / \omega_{3}$ ) implying that country 1's relative wage ratio with country 3 to improve (higher $\omega_{3}$ ). The change in the relative factor price affects indirectly all other borderline goods $z_{k}$, as illustrated in Table 1b.

\footnotetext{
${ }^{14}$ Note, in case that the real income change of country 2 is larger in comparison to country 1 , that is, $N_{1} a_{2}\left(z_{3}\right) z_{3}\left(\tau_{12}-1\right)<N_{2} a_{1}\left(z_{1}\right) z_{1}\left(\tau_{21}-1\right)$, country 3's trade balance turns into a deficit, regardless of the values for $\zeta$ and $\zeta_{2}$. We exclude this possibility and assume for the remainder of the paper that $N_{1}>N_{2}>N_{3}$, ensuring that country 1 is the poorest country while country 3 the richest.
} 


\section{Formation of Preferential Trade Agreements between Heterogeneous Countries}

We now proceed with investigating the effects of the formation of preferential trade agreements (PTAs) on global specialization and terms of trade. Before we discuss our main findings, it is useful to point out that establishing the effects of PTAs essentially boils down to adding the general equilibrium effects of the relevant unilateral tariff reductions that were discussed in the previous section. ${ }^{15}$ The reasoning we will employ therefore consists of the same two main effects we have seen before. The first effect is that when tariffs come down, the competitiveness of a country's industries is affected, and thereby the derived demand for labor. The second effect is that the formation of PTAs also affects the ranges of non-traded goods, by which real income effects accrue that affect spending on goods from either country 3 (as in the symmetric trade equilibrium) or from country 2 and country 3 (as in the asymmetric trade equilibrium). Both effects have consequences for the relative wages in the three countries, leading to the general equilibrium effects discussed below. ${ }^{16}$

PTA between countries 2 and $3\left(P^{2} A_{23}\right)$.

Consider first the formation of a PTA between the high-income country 3 and the middle-income country 2 , a situation which would resemble the recent enlargement of the EU to the east. This implies a reduction of the bilateral tariffs $\tau_{23}$ and $\tau_{32}$, while leaving all other tariffs at their initial values. Consequently, at initial factor prices, the member countries will expand their imports from each other, that is $z_{2}-z_{4}$ increases while $z_{6}$ falls:

$$
\frac{\widehat{z}_{2}}{\widehat{\tau}_{32}}=\frac{1}{\zeta_{2}}>0, \quad \frac{\widehat{z}_{4}}{\widehat{\tau}_{32}}=-\frac{1}{\zeta}<0, \quad \frac{\widehat{z}_{6}}{\widehat{\tau}_{23}}=\frac{1}{\zeta}>0
$$

where the 'hat' notation is used to express relative changes, e.g. $\widehat{\tau}$ is defined as $d \tau / \tau .{ }^{17}$ These competition effects are the same regardless the type of equilibrium we consider (symmetric, asymmetric) and are the result of the change in competitiveness of country

\footnotetext{
${ }^{15} \mathrm{~A}$ detailed appendix containing all the derivatives is available in an appendix upon request from the authors.

${ }^{16}$ Traditionally, the analysis of the formation of PTAs has been formulated in terms of trade diversion and trade creation. For general equilibrium analyses this terminology fails to capture all aspects of discriminatory trade liberalization. Nevertheless, some elements in our analysis bear resemblance with the old concepts. The reduction in non-traded areas of a PTA between contiguous countries can be seen as trade creation in the standard Vinerian sense. Likewise, switching the source of imports due to PTA formation can be seen as trade diversion.

${ }^{17}$ By concentrating on marginal tariff changes in contrast to complete discrimination our results shed light on the initial effects of PTAs.
} 
2 and country 3 producers on each other's markets. As before, the extent to which the tariff changes affect competitiveness depends on the degree of comparative advantage at the specific borderline commodity, as indicated by $\zeta$ and $\zeta_{2}$. The initial competition effects influence labor markets and adjustments in the bilateral terms of trade of countries are required to restore equilibrium. Moreover, it leads to spending effects that either reinforce or counter these labor market developments. The general equilibrium effects of $\mathrm{PTA}_{23}$ are given in Table 2. We note that the results are typically the same for both equilibrium settings, except for some slight but telling changes in conditions.

\section{(insert Table 2 about here)}

The effects on $z_{1}, z_{2}, z_{3}$ and $\omega_{2}$ are unambiguous, which is related to the fact that the effect of a fall in $\tau_{23}$ on these variables is zero. In determining the signs for the other variables we see that $\zeta$ and $\zeta_{2}$ play a key role. We therefore discuss the table by considering the effects when $\zeta$ is small (for $\zeta_{2}>0$ ), to then verify the results if instead $\zeta_{2}$ is small (for given $\zeta>0)$.

Suppose $\zeta_{2}>0$ and $\zeta$ is small, that is unit labor requirements between countries 2 and 3 are very similar. This implies that the initial competition effects are dominated by the upward effect on $z_{4}$ and the downward effect on $z_{6}$ (the effect on $z_{2}$ is of course still there and indeed nicely explains the negative impact on $\omega_{2}$ ). The upward effect on $z_{4}$ increases the derived demand for country 2's labor and lowers it for country 3's labor, while the downward effect on $z_{6}$ does exactly the opposite. Consequently, the net competition effect on $\omega_{2} / \omega_{3}$ depends on each country's marginal expenditure rate: if $N_{3} a_{2}\left(z_{4}\right) z_{4}<N_{2} a_{2}\left(z_{6}\right) z_{6}$ the effect on $z_{6}$ dominates and $\omega_{2} / \omega_{3}$ increases, deteriorating country 2 's factor terms of trade vis-à-vis country 3 . The real income effects that accrue are positive, as both country 2 and country 3 may welcome a decline in their non-traded goods ranges. These real income gains are spent on country 3 goods for both equilibrium settings, which increases demand for country 3 labor, yielding additional upward pressure on country 3's relative wage.

Suppose now that the unit labor requirements between country 1 and country 2 are ceteris paribus more equalized, that is $\zeta_{2}$ is small for given $\zeta>0$. In this case, the competitive effect on $z_{2}$ dominates the initial effects. As the range of goods country 1 exports to country 3 falls (lower $z_{2}$ ), the derived demand of country 3 households for country 2's labor increases at the expense of demand for country 1's labor. This explains the negative signs for $\omega_{2}$ and for $\omega_{3}$ in the asymmetric equilibrium. As both effects relate to country 3 demand, the relative size of country 2 and country 3 does not play a role. Rather it is the relative size of country 1 and country 2 that might matter. The decline 
in $z_{2}$ lowers the non-traded goods range for country 2 , but increases it for country 1 . In the symmetric trade equilibrium, both countries spend their marginal income on goods from country 3, explaining why the general equilibrium effect on $\omega_{2} / \omega_{3}$ depends on the relative size of country 1 and country 2 . The bigger (smaller) country 1 is, the bigger (smaller) the reduction in spending on country 3 goods, yielding a negative (positive) effect on the bilateral factor terms of trade of country 3 vis-à-vis country 2 , i.e. $\omega_{2} / \omega_{3}$ goes down (up). By contrast, in the asymmetric trade equilibrium, the negative real income effect in country 1 leads to less spending on country 2 goods, whereas the positive real income effect in country 2 still accrues to country 3 goods. This explains why in the asymmetric equilibrium configuration the relative size of country 1 and country 2 does not matter when $\zeta_{2}$ is small. Moreover, the spending effects give rise to an upward pressure on the bilateral factor terms of trade of country 3 vis-à-vis country 2 , explaining why $\omega_{2} / \omega_{3}$ is positive.

\section{PTA between countries 1 and $2\left(P T A_{12}\right)$}

Consider next the formation of a PTA between the low-income country 1 and the middleincome country 2. This implies a reduction of the bilateral tariffs $\tau_{12}$ and $\tau_{21}$, ceteris paribus. As examples of such kind of arrangements might serve the recent establishment of free trade areas between Turkey and Morocco and Turkey and Tunisia as well as those between the Kyrgyz Republic and Kazakhstan, the Kyrgyz Republic and Moldovia and the Kyrgyz Republic and Armenia. ${ }^{18}$ The general equilibrium effects of $\mathrm{PTA}_{12}$ are presented in Table 3 and can be explained by focusing on the initial competition and real income effects.

The initial competition effects on $z_{1}, z_{3}$ and $z_{5}$, while keeping relative wages constant, are

$$
\frac{\widehat{z}_{1}}{\widehat{\tau}_{21}}=-\frac{1}{\zeta_{2}}<0, \quad \frac{\widehat{z}_{3}}{\widehat{\tau}_{12}}=\frac{1}{\zeta_{2}}>0, \quad \frac{\widehat{z}_{5}}{\widehat{\tau}_{12}}=-\frac{1}{\zeta}<0,
$$

where we note that the effect on $z_{5}$ only arises in the symmetric equilibrium configuration. The changes in competitiveness yield both countries better access to each other's markets, the extent of which is determined by the indicator of comparative advantage at both borderline goods, $\zeta_{2}$. In the symmetric trade equilibrium, the improved access to each other's markets goes at the expense of the country that remains outside the agreement, increasing $z_{5}$. For this effect $\zeta$ is the important parameter.

If $\zeta$ is small, the upward effect on $z_{5}$ dominates the effects for the symmetric trade equilibrium. It increases demand for country 2 labor and decreases that for country 3

\footnotetext{
${ }^{18}$ According to the World Bank classification, Turkey is an upper-middle-income economy, Tunisia, Morocco, Armenia, Moldavia and Kazakhstan are all lower-middle-income economies, and the Kyrgyz Republic is a low-income economy.
} 
labor. The real income effects accrue because of changes in non-traded goods areas. In this case, the non-traded goods range of country 2 decreases while that of country 3 increases. As both countries spend their marginal income on country 3 goods, the net effect will be negligible compared to the competition effect, explaining the negative general equilibrium effect on $\omega_{2} / \omega_{3}$ and the fact that it is independent on the relative size of countries. ${ }^{19}$

For small $\zeta_{2}$, the competitive effect on $z_{1}$ and $z_{3}$ dominates the initial effects. As country 2 's imports from country 1 goes up (higher $z_{1}$ ), the derived demand of country 2 households for country 1's labor increases at the expense of demand for its own labor force. Likewise, the increase in country 1's imports from country 2 ( larger $z_{3}-z_{5}$ ), increases the derived demand of country 1 households for country 2 labor, at their own expense. This explains the negative sign for $\omega_{2}$ and why it depends on the relative size of country 1 with respect to country 2, also when $\zeta_{2}>0$. The income effects are as follows. The increase of $z_{1}$ reduces the non-traded goods range for country 2 , just like the decrease in $z_{3}$ reduces it for country 1 . In the symmetric trade equilibrium both countries spend their marginal income on country 3 goods, explaining the increase of the bilateral factor terms of trade of country 3 vis-à-vis country 1 ( $\omega_{3}$ down). Taking the competition effects and the spending effects together, $\omega_{2} / \omega_{3}$ goes up for small $\zeta_{2}$. In the asymmetric equilibrium setting, the spending effects of country 1 accrue instead to country 2 goods. This has no effect on the sign for $\omega_{3}$, though the magnitude of its positive effect will be less than before as only the spending effect of country 2 remains. Consequently, also the sign for $\omega_{2} / \omega_{3}$ remains clear.

\section{(insert Table 3 about here)}

\section{PTA between countries 1 and $3\left(P T A_{13}\right)$}

Consider finally the formation of a PTA between the low-income country 1 and the high-income country 3. As an example might serve the preferential trade arrangement the EU has with the ACP countries under the Lomé convention. This implies, ceteris paribus, a reduction of the bilateral tariffs $\tau_{13}$ and $\tau_{31}$, leading to an increase in trade between member countries due to the increase in $z_{2}$ and fall in $z_{5}$ at initial factor prices:

$$
\frac{\widehat{z}_{2}}{\widehat{\tau}_{31}}=-\frac{1}{\zeta_{2}}<0, \quad \frac{\widehat{z}_{5}}{\widehat{\tau}_{13}}=\frac{1}{\zeta}>0,
$$

\footnotetext{
${ }^{19}$ Of course, we realize that the simple reasoning we continuously apply can never give the exact story behind the results. In a way, this is proven by the unclear sign that arises in the asymmetric case. The question mark appears because we can derive that when $\zeta$ equals zero, the general equilibrium effect on $\omega_{2} / \omega_{3}$ is zero as well. If $\zeta$ approaches zero, however, we are not sure from which side $\omega_{2} / \omega_{3}$ approaches zero. The complex condition we could derive for that in fact includes relative sizes of countries.
} 
where the impact on $z_{5}$ again only holds for the symmetric trade equilibrium. The general equilibrium effects of $\mathrm{PTA}_{13}$ are presented in Table 4 . We note that the effects are to a large extent opposite to that of $\mathrm{PTA}_{23}$ and that the asymmetric trade equilibrium involves no ambiguities. The latter is due to the fact that country 1 does export but does not import from country 3 in the asymmetric trade equilibrium. For both types of equilibria, the competition effects imply that trade between the two member countries expands. Since both countries are non-contiguous, this trade expansion goes completely at the expense of country 2's exports. For small $\zeta$ the downward effect on $z_{5}$ dominates all other effects (the positive effect on $z_{2}$ again nicely serves to explain the positive impact on $\omega_{2}$ ). Country 1 's reduction of imports from country 2 reduces demand for country 2 labor and increases demand for country 3 labor, resulting in a terms of trade improvement for country 3 with country 2 , that is $\omega_{2} / \omega_{3}$ goes up. For the real income effects it is important that in this case the non-traded goods range of country 2 increases $\left[\left(z_{2}-z_{1}\right)\right.$ and $\left(z_{6}-z_{5}\right)$ go up] and that of country 3 decreases. As households in both countries spend their marginal income in country 3 , the net effect will be negligible compared to the competition effect, explaining the general equilibrium effect on $\omega_{2} / \omega_{3}$ and the fact that it is independent of the relative size of countries.

On the other hand, if $\zeta_{2}$ is small relative to $\zeta$, the competitive effect on $z_{2}$ dominates the initial competition effects. As it increases, the derived demand of country 3 households for country 2 labor decreases in favor of demand for country 1 labor. This explains the positive signs for $\omega_{2}$ and $\omega_{3}$ (asymmetric trade equilibrium). The increase of $z_{2}$ increases the non-traded goods range for country 2 , but lowers it for country 1 . In the symmetric trade equilibrium both countries spend their marginal income on country 3 goods, explaining why the general equilibrium effect on $\omega_{2} / \omega_{3}$ depends on the relative size of country 1 and country 2. The bigger (smaller) country 2 , the bigger (smaller) the reduction in spending on country 3 goods, yielding a negative (positive) effect on the bilateral factor terms of trade of country 3 vis-à-vis country 2, i.e. $\omega_{2} / \omega_{3}$ down (up). By contrast, in the asymmetric trade equilibrium the income effect in country 1 leads to increased spending on country 2 goods, whereas the income effect in country 2 still reduces spending on country 3 goods. This explains that in the asymmetric trade equilibrium the relative size of country 1 and country 2 does not matter anymore when $\zeta_{2}$ is small. Moreover, the spending effects give rise to a further downward pressure on the bilateral factor terms of trade of country 3 with respect to country 2 , explaining that $\omega_{2} / \omega_{3}$ is negative.

(insert Table 4 about here) 


\section{General insights}

Having established the general equilibrium effects for the alternative PTA arrangements, a first general insight is that the formation of a PTA affects factor prices and efficient production by and large similarly for both the symmetric trade equilibrium and the asymmetric trade equilibrium. Except for some telling differences in conditions, the signs we obtain are typically invariant to the equilibrium configuration under consideration.

Another insight that emerges, is that a PTA does not necessarily results in a deterioration in the terms of trade of the nonmember country. Here the income level of the nonmember is crucial. Leaving the specific conditions aside, it appears that whereas a poor country is more likely to experience both of its bilateral factor terms of trade to decline, for a rich country there is fair chance that its bilateral terms of trade improve. The mediumrich country is somewhere in between. This result is a direct consequence of the fact that in our framework goods are not gross substitutes. This ensures that positive real income effects that are brought about by lower prices of lower-ranked goods increase demand for higher-ranked goods; country 3 goods in the symmetric case and also country 2 goods in the asymmetric case.

Finally, our results indicate that the degree of comparative advantages between countries, as measured by $\zeta_{2}$ and $\zeta$, is crucial. This is because our model does not impose any restriction on $\zeta_{2}$ and $\zeta$. This is key to understanding the bilateral terms of trade effects between the high-income country and either the middle-income or the low-income country $\left(\omega_{2} / \omega_{3}\right.$ and $\left.\omega_{3}\right)$. It has no bearing on the bilateral terms of trade of PTAs between the low-income and middle-income country $\left(\omega_{2}\right)$.

\section{Welfare effects of PTAs}

In the previous section we have examined the resource allocation and terms of trade effects of economic integration when countries differ significantly in their level of income. One of the outcomes has been that the formation of a PTA affects factor prices and efficient production by and large similarly, regardless of whether we considered the symmetric trade equilibrium or the asymmetric trade equilibrium. Qualitatively the extent of global income disparities therefore does not seem to matter for the effects of PTA formation. In this section, we show that it does when considering the welfare effects of PTA formation.

The welfare effects of PTA formation are obtained by differentiation of the budget constraints (16)-(18), assuming $\tau_{j k}=\tau_{j k^{\prime}}$ for $j, k, k^{\prime}=1,2,3$, for given productivity parameters (see Appendix D for details). For the symmetric trade equilibrium this yields for country 


$$
a_{3}\left(u_{1}\right) d u_{1}=\frac{\omega_{3}}{\omega_{2}} \int_{z_{3}}^{z_{5}} a_{2}(s) d s \widehat{\omega}_{2}+\int_{z_{5}}^{u_{1}} a_{3}(s) d s \widehat{\omega}_{3}+\frac{\omega_{3}}{\omega_{2}} a_{2}\left(z_{3}\right) z_{3}\left(1-\tau_{12}\right) \widehat{z}_{3},
$$

for country 2

$$
\begin{aligned}
a_{3}\left(u_{2}\right) d u_{2}= & -\frac{\omega_{3}}{\omega_{2}}\left[1-\int_{z_{1}}^{z_{6}} a_{2}(s) d s\right] \widehat{\omega}_{2}+\int_{z_{6}}^{u_{2}} a_{3}(s) d s \widehat{\omega}_{3} \\
& +\omega_{3} a_{1}\left(z_{1}\right) z_{1}\left(\tau_{21}-1\right) \widehat{z}_{1}-a_{3}\left(z_{6}\right) z_{6}\left(\tau_{23}-1\right) \widehat{z}_{6},
\end{aligned}
$$

and for country 3

$$
a_{3}\left(u_{3}\right) d u_{3}=\frac{\omega_{3}}{\omega_{2}} \int_{z_{2}}^{z_{4}} a_{2}(s) d s \widehat{\omega}_{2}-\left[1-\int_{z_{4}}^{u_{3}} a_{3}(s) d s\right] \widehat{\omega}_{3}+\left(\tau_{32}-1\right) \frac{\omega_{3}}{\omega_{2}} a_{2}\left(z_{4}\right) z_{4} \widehat{z}_{4} .
$$

For the asymmetric equilibrium, the expression for country 1 becomes, instead of (22):

$$
a_{2}\left(u_{1}\right) d u_{1}=\int_{z_{3}}^{u_{1}} a_{2}(s) d s \widehat{\omega}_{2}-\left(\tau_{12}-1\right) a_{2}\left(z_{3}\right) z_{3} \widehat{z}_{3},
$$

while the expressions for country 2 and country 3 remain the same. The first term(s) on the right hand side in (22)-(24) and (25) represent the factor terms of trade effect(s) weighted by the country's value of imports. The second terms reflect the impact on real income via changes in the range of non-traded goods. This latter term can also be interpreted as the change in deadweight loss caused by the change in the import volume as a result of the change in the range of non-traded goods. Since we started from a tariff-ridden equilibrium there is also a price effect of lower tariffs on the tariff revenues, holding quantity constant. This price effect drops out since, with homogeneous population, the gains of lower prices of imported goods is exactly matched by lower tariff rebates. The absence of $\omega_{3}$ in (25) in comparison to (22) follows from the fact that country 1 does only export but not import goods from country 3 in the asymmetric trade equilibrium.

The welfare effects are presented in Table 5. We first consider the case where the poor country is not part of a PTA, that is $\mathrm{PTA}_{23}$. When country 1 is too poor to import from country 3 the welfare of its households deteriorates on account of the increase in the range of goods produced locally ( $z_{3}$ increases) and on account of the deterioration of its terms of trade with country 2 ( $\omega_{2}$ falls). As country 1's terms of trade with country 3 also tends to deteriorate $-\omega_{3}$ falls for low enough $\zeta_{2}-d u_{1}<0$ and country 1's welfare deteriorates. This result also holds when country 1 is rich enough to import from country 3 , be it under similar conditions that were needed to resolve the ambiguity in the effect on $\omega_{3}$.

On the other hand, the poorest country is likely to gain when being a member of a PTA. In case country 1 is so poor that it does not import from country 3, a PTA with either country 2 or country 3 is beneficial as long as $\zeta_{2}$ is sufficiently small. A union with 
country 3 is to the benefit of country 1 , and depends only on the degree of comparative advantage, that is: $d u_{1}>0$ if $\zeta_{2}$ is sufficiently small. When $\zeta$ is small this also holds for $\mathrm{PTA}_{13}$. The welfare effect for $\mathrm{PTA}_{12}$ is then unclear, which is related to the positive effect on $\omega_{3}$ when $\zeta$ is low. We note that when country 1 can afford imports from country 3 , the welfare effects are typically reversed or ambiguous. Apparently, it pays off to be poor when engaging in preferential trade.

What can we say about the welfare effects for the other two countries? We infer from the table that $\mathrm{PTA}_{23}$ gives the clearest results on the welfare of country 2 and country 3. An agreement between the medium rich and the rich country is welfare improving for both country 2 and 3 if $\zeta$ is small (this holds for both equilibrium settings). Being contiguous, a low $\zeta$ implies that the range of non-traded goods in both countries reduces considerably and large real income gains result, $d u_{2}>0, d u_{3}>0$. When $\zeta_{2}$ is low, it is important for understanding the welfare effects where country 1 households spend their marginal income. If the real income losses in country 1 imply reduced spending on country 3 goods (symmetric trade equilibrium), country 3 loses; if they imply reduced spending on country 2 goods (asymmetric trade equilibrium), country 2 loses. With respect to the effects of the other two PTAs the noteworthy result is that when country 1 is too poor to import from country 3 , the preferred strategy for country 3 is not to engage in a PTA with country 1 , but to encourage a $\mathrm{PTA}_{12}$. The absence of a positive spending effect of country 1 consumers on country 3 goods once again explains why this is the case. A similar reasoning holds of course for country 2. When country 1 households are rich enough to afford country 3 goods, some of these results reverse, emphasizing the importance of income differences for understanding the welfare effects of PTAs.

\section{(insert Table 5 about here)}

This leads to the following general conclusions. First, being a member of a PTA is no guarantee for welfare improvements. The only exception seems to be when a country is too poor to afford the whole range of products the world has to offer. Else the welfare effects of being a member or not depend on the extent to which comparative advantages differ, both between the member countries and with respect to nonmember countries. Secondly, it appears that being not a member of a PTA does not necessarily lead to welfare losses. The odds are now against the poorer countries, however. The more one produces at the higher end of the goods spectrum (here country 3), the more likely it is that being left outside is not detrimental to welfare. This is due to the presence of asymmetric demand complementarities. Whereas the outside country suffers as the PTA members' expenditure 
switching goes at their expense, the ensuing real income gains of the members may compensate for this. Third, it appears that not only the income differences per se matter for the welfare results of PTAs, but also the extent of these income differences. While being a low income country leads to different inferences regarding the costs and benefits of preferential trading agreements than being a middle- or high-income country, it also holds that these results depend highly on whether or not the low-income country is partly insulated from world trade. Consequently, income differences between countries are of crucial importance to gauge the welfare effects of preferential trade liberalization.

We finally note that our deliberations on welfare also point at another interesting aspect of our framework. In contrast to the standard literature on the formation of preferential trade agreements, including $\mathrm{ACF}$, in the present model the range of industries producing in the world economy is not fixed. Increases in $u_{3}$, the highest indexed good that is consumed, can be interpreted as an expansion of the global range of products. The real income gains experienced by the richest households in the world provide an incentive for entrepreneurs in the high-income country to invent new products. The present model can explain the emergence of new industries in the world economy as well as the emergence of product life cycles as discussed by Vernon (1966).

\section{$7 \quad$ Multilateral, regional or unilateral?}

In the previous section we have analyzed the welfare gains from the formation of PTAs. However, gains from integration can also be achieved from multilateral and unilateral tariff reductions. This section explores how alternative forms of integration - unilateral, preferential or multilateral - matter for the welfare effects of integration when countries differ in income and produce goods with different income elasticities. ${ }^{20}$

The comparative static effects of unilateral tariff reductions were presented in Table 1 and have been discussed in Section 4. The concomitant welfare effects are given in Table 6a (symmetric trade equilibrium) and Table $6 \mathrm{~b}$ (asymmetric trade equilibrium).

\section{(insert Table $6 a$ and $6 b$ about here)}

Table 6a indicates that the poorest country, country 1, is by and large worse off from unilateral tariff changes the more uniform are unit labor requirements in industries across

\footnotetext{
${ }^{20}$ The analysis therefore also has a bearing on the Johnson-Cooper-Massel proposition, which claims that unilateral tariff reductions are most lilely to welfare dominate preferential trade arrangements. See e.g. Pomfret (2001) for an overview of the discussion.
} 
country 1 and country 2 (small $\zeta_{2}$ ) and the larger is $\zeta$. In this case the deterioration in country 1's relative wage with country 3 dominates all other effects. Consequently, households from country 1 experience significant real income losses, inducing them to reduce their range of consumption $\left(d u_{1}<0\right)$. If country 1 is too poor to fully engage in world trade, as in the asymmetric trade equilibrium, a unilateral tariff reduction is beneficial if $\zeta_{2}$ is small. Under the same conditions, country 3 is much more likely to gain from unilateral tariff changes as the positive spending effects abroad accrue to country 3 goods. The exception is of course reducing $\tau_{31}$ in the asymmetric trade equilibrium, as country 3 does not export to country 1 . For country 2 the results are mixed.

The general equilibrium effects of multilateral tariff reductions are given in Table $7 \mathrm{a}$. At initial relative wages, this yields the following impact effect on competitiveness

$$
\frac{\widehat{z}_{1}}{\widehat{\tau}}=-\frac{1}{\zeta_{2}}<0, \quad \frac{\widehat{z}_{2}}{\widehat{\tau}}=0, \quad \frac{\widehat{z}_{3}}{\widehat{\tau}}=\frac{1}{\zeta_{2}}>0, \quad \frac{\widehat{z}_{4}}{\widehat{\tau}}=-\frac{1}{\zeta}<0, \quad \frac{\widehat{z}_{5}}{\widehat{\tau}}=0, \quad \frac{\widehat{z}_{6}}{\widehat{\tau}}=\frac{1}{\zeta}>0,
$$

for $\hat{\tau}_{i j}=\hat{\tau}<0$ for $i, j=1,2,3$ and $i \neq j$. Reducing tariff rates proportionally across all nations only affects the borderline commodities that delineate non-traded goods and traded goods. Accordingly, labor demand for country 1's labor force declines because its highestranked goods are lost to country 2 , while at the same time it increases because country 2 loses some of its lower-ranked goods to country 1. Likewise labor demand effects arise for country 2 and 3 . The effect of this on the bilateral factor terms of trade of each country is related to the strength of their respective comparative advantages at the borderline commodities, $\zeta_{2}$ and $\zeta$. As all countries see their ranges of non-traded goods decline, the initial real income effects work in favor of country 3's labor (symmetric trade equilibrium) or in favor of both country 2's and country 3's labor (asymmetric trade equilibrium). This implies that if country 3 's competitiveness is initially unaffected, i.e. $\zeta_{2}$ is sufficiently small, its bilateral factor terms of trade will improve across the board for both equilibrium settings. The effect on $\omega_{2}$ depends on the relative size of country 1 and country 2 . On the other hand, if $\zeta$ is sufficiently small, it is country 1 that is initially shielded from the competition effects. The initial impact on $z_{4}$ and $z_{6}$ dominate effects and the relative sizes of country 2 and 3 become important for $\omega_{2} / \omega_{3}$. Absent initial effects, the impact on country 1's terms's of trade still depends on its relative size with respect to country 2 .

Table $7 \mathrm{~b}$ gives the welfare effects of multilateral tariff reductions. When the income differences between countries are not too significant (symmetric trade equilibrium), the rich country is most likely to gain from multilateral trade liberalization, while the poor country stands a fair chance to lose. When the poor country's income is so low that it cannot afford country 3 goods, also country 1 gains. 
(insert Table $7 a$ and $7 b$ about here)

Comparing the welfare results of the three different types of integration, only for country 2 and country 3 some qualitative differences can be discerned. On many occasions our analysis does not reveal a clear ranking of integration types. This is particularly true for country 1. Cutting tariffs unilaterally, engaging in preferential trade arrangements or going the multilateral way, qualitatively the welfare effects are the same. If country 1 is too poor to be fully engaged in world trade, cutting tariffs is beneficial, while if it is rich enough to also import from country 3 , cutting tariffs is bad. For country 2 and country 3 we can establish some ranking though. Country 3 would seem to prefer multilateral tariff reductions over unilateral tariff reductions, while in the symmetric trade equilibrium it also has a weak preference for establishing $\mathrm{PTA}_{13}$ over unilaterally reducing $\tau_{31}$. By the same token, country 2 seems to prefer $\mathrm{PTA}_{23}$ over a unilateral cut in $\tau_{23}$. Country 3 clearly prefers multilateral tariff reductions over $\mathrm{PTA}_{13}$ if country 1 is too poor to buy its products. This turns into a weak preference for $\mathrm{PTA}_{23}$ if country 1 is rich enough to buy country 3 produce. Country 2, by contrast, then seems to have a weak preference for establishing $\mathrm{PTA}_{23}$ over multilaterally reducing tariffs.

Numerical simulations will be necessary to shed further light on the relative preference of countries for either type of integration. For now, the conclusion seems valid that rich countries are inclined to favor the multilateral process and that for medium-rich countries it all depends. Being in direct competition with both rich and poor countries implies that the exact conditions prior to liberalizing trade are crucial for establishing the preferred type of integration. Poor countries are invariant to the particular type of integration. For them it is the extent of their poverty that matters. The poorer the country, the more globalization has to offer.

Finally, from the perspective of the appearance of new industries, multilateral reduction of tariffs has most to offer in that respect. Engaging in PTA formation might also be conducive to the growth of new industries, provided the income disparity between members is not too large.

\section{Concluding remarks}

This paper examines the effects of preferential trade agreements (PTAs) on resource allocation and welfare when countries differ in their stage of economic development. Traditionally, international economists have made the simplifying assumption of homothetic preferences 
when analyzing the formation of preferential trade agreements. The homotheticity assumption implies that all goods have the same unitary income elasticities and that poor and rich households alike consume all available goods in the same proportion. In light of a growing trend towards regional integration agreements between with countries of substantially different income levels, we claim that assuming homothetic preferences is too far-fetched. We therefore develop a three-country Ricardian trade model in which consumers rank goods according to priority. The poorest country, country 1 , has a comparative advantage in the production of lower ranked goods, and, hence specializes in goods with lower income elasticities in demand. The richest country, country 3 , has a comparative advantage in the production of the highest-ranked goods, and hence, specializes in goods with higher income elasticities in demand. The medium-rich country, country 2, has a comparative advantage in the production of the intermediate-ranked commodities. Goods at the lower end of the spectrum are consumed by all households and when income increases households add higher-ranked goods to their consumption basket.

We come to the following conclusions. First, a PTA does not necessarily deteriorate the terms of trade of the country that is left outside of the agreement, though this very much depends on the income level of the nonmember. We show that being a nonmember implies for the poor country that its terms of trade typically deteriorate, while for a rich country the terms of trade may still improve. Second, being left outside a PTA agreement is usually bad for welfare, except for the rich country. This is due to the presence of asymmetric demand complementarities. Whereas the outside country suffers as the PTA members' expenditure switching goes at their expense, for a rich country this might be compensated by the way the PTA members spend their real income gains. These are normally spent on country 3 goods only, explaining why the chances on welfare improvement for a nonmember are higher the richer is the country. Third, being a member of a PTA is no guarantee for welfare improvements. Only countries that are too poor to import the whole range of world products can be assured that opening up their borders preferentially leads to welfare gains. For the other countries it depends to a large extent on how comparative advantages differ across the world.

The general conclusion is that the income level of a country greatly matters for assessing the welfare effects of PTAs. Being a low-income country leads to different inferences regarding the costs and benefit of preferential trading agreements than being a middle- or high-income country. Moreover, it is not only the income differences per se that matter for the welfare results of PTAs, but also the extent of these income differences. For instance, if the poor country's income level is so low that it is partly insulated from world trade, our analysis shows that it will gain by joining a preferential trade agreement with a richer 
counterpart. If instead the poor country's income level is such that it also imports the higher-ranked goods, we show that it loses from PTA formation.

There are several ways to extend our current analysis. One could easily allow for nondegenerate income distributions, $F_{j}\left(h_{j}\right)$. While this extension would make the trade balance conditions directly dependent on relative factor prices, the more important issue that arises is how to redistribute tariff revenues among households. As shown in Stibora and de Vaal (2006), using a two country set-up, allowing for nondegenerate income distributions is inconsequential for the essential allocation and terms of trade results.

Second, by considering only small changes in tariffs, we have ruled out the possibility of switching from an asymmetric trade equilibrium to a symmetric equilibrium (or vice versa). Intuitively, we would expect that such regime switches will not qualitatively affect our results, but quantitatively they might. By performing numerical simulations we hope to shed some light on this matter. Simulations are also useful to compare the welfare outcomes of different trade regimes. In particular, it might help to unravel the specific circumstances under which either of the integration regimes would be preferred. In the paper we have given some consideration to the welfare implications of alternative forms of integration (PTA, multilateral, unilateral). On most occasions this does not reveal clear preferences by countries for a particular form of integration, though it would seem that rich countries prefer the multilateral process. For poor countries it is not so much the particular type of integration that is important, but rather the extent of their poverty. Globalization has more to offer, the poorer they are. Simulations will also be helpful for assessing the quantitative differences between the two equilibrium configurations of our analysis.

\section{References}

[1] Appleyard, D.R., P.J. Conway, and A.J. Field, Jr. 1989. "The Effects of Customs Unions on the Pattern and Terms of Trade in a Ricardian Model with a Continuum of Goods." Journal of International Economics, 27: 147-164.

[2] Baldwin, R and Ch. Wyplosz. 2003. The Economics of European Integration, McGrawHill.

[3] Berglas, E. 1979. "Preferential Trading Theory: n Commodity Case." Journal of Political Economy, 87: 315-331.

[4] Bertola, G., R. Foellmi and J. Zweimüller. 2006. Income distribution and macroeconomic models, Princeton University Press, Princeton and Oxford. 
[5] Bhagwati, J. and A. Panagariya. 1996. The Economics of Preferential Trade Agreements, The AEI Press, Washington, D.C.

[6] Burenstam Linder, S. 1961. An essay on trade and transformation, Wiley, New York.

[7] Conway, P.J., D.R. Appleyard, and A.J. Field, Jr. 1989. "Trade agreements vs. unilateral tariff reductions: evidence from modeling with a continuum of goods." International Economic Review, 30: 775-794.

[8] Flam, H., and E. Helpman. 1987. "Vertical Product Differentiation and North-South Trade." American Economics Review 77, 810-822.

[9] Helpman, E., M. Melitz, and Y. Rubinstein. 2005. "Trading Partners and Trading Volumes." Mimeo, Harvard University.

[10] Hicks, J.R. and R.G.D. Allen. 1934. "A Reconsideration of the Theory of Value. Part I." Economica, 1:52-67.

[11] Hunter, L.C. 1991. "The Contribution of Nonhomothetic Preferences to Trade." Journal of International Economics 30, 345-58.

[12] Hunter, L.C. and J.R. Markusen. 1987. "Per-Capita Income as a Determinant of Trade," in: R. Feenstra (ed.), Empirical Method for International Trade. Cambridge, Mass.: MIT Press.

[13] Krishna, K. and C. Yavas. 2005. "When Trade hurts: Consumption Indivisibilities and Labor Market Distortions." Journal of International Economics, 67: 413-427.

[14] Lederman, W. 1966. Multiple Integrals. Routledge \& Kegan Paul.

[15] Matsuyama, K. 2000. "A Ricardian Model with a Continuum of Goods under Nonhomothetic Preferences: Demand Complementarities, Income Distribution, and NorthSouth Trade." Journal of Political Economy, 108: 1093-1120.

[16] Meade, J.E. 1955. The Theory of Customs Unions, Amsterdam.

[17] Mitra, D. and V. Trindade. 2005. "Inequality and trade", Canadian Journal of Economics, 38(4): 1253-1271.

[18] Mundell, R. 1964. "Tariff preferences and the terms of trade." Manchester School of Economics and Social Studies, 1-13 (reprinted in Bhagwati, J., P. Krishna, and A. Panagariya (1999), Trading Blocs, Alternative approaches to analyzing preferential trade agreements. Cambridge, Mass.: MIT Press, 145-156). 
[19] Murphy, K., A. Shleifer, and R.W. Vishny. 1989. "Income Distribution, Market Size, and Industrialization." Quarterly Journal of Economics, 104: 537-64.

[20] Panagariya, A. 2000. "Preferential trade liberalization: The traditional theory and new developments." Journal of Economic Literature, 38 (2): 287-331.

[21] Pomfret, P.K. 2001. The Economics of Regional Trade Arrangements. Oxford: Oxford University Press.

[22] Schott, P.K. 2001. "Do rich and poor countries specialize in a different mix of goods? Evidence from Product level U.S. Trade Data." NBER Working paper, no. 8492, NBER, Washington, D.C.

[23] Stibora, J. and A. de Vaal. 2006. "Trade Policy in a Ricardian Model with a Continuum of Goods under Nonhomothetic Preferences." forthcoming in the Journal of Development Economics.

[24] Stokey, N.L. 1991. "The Volume and Composition of Trade between Rich and Poor Countries." Review of Economic Studies 58, 63-80.

[25] World Trade Organization. 2002. Regional Trade Integration under Transformation, Geneva: WTO Trade Policies Review Division. 


\section{A Labor market equilibria}

\section{A.1 Labor market condition for country 1}

Here we derive equation (11) given in the main text. Using (10), we note

$$
\begin{aligned}
L_{1} & =N_{1} \int_{0}^{\infty} h_{1} d F_{1}\left(h_{1}\right) \\
& =\int_{0}^{z_{3}} a_{1}(z) Q_{1}(z) d z+\int_{0}^{z_{2}} a_{1}(z) Q_{3}(z) d z+\int_{0}^{z_{1}} a_{1}(z) Q_{2}(z) d z .
\end{aligned}
$$

For clarity, let us expand the expenditure expressions, given in equation (7), as follows

$$
\begin{array}{ll}
E_{1}(z)=\int_{0}^{z} w_{1} a_{1}(s) d s \quad \text { for } z \leq z_{3} \\
E_{2}(z)=\tau_{21} \int_{0}^{z} w_{1} a_{1}(s) d s \quad \text { for } z \leq z_{1} \\
E_{3}(z)=\tau_{31} \int_{0}^{z} w_{1} a_{1}(s) d s \quad \text { for } z \leq z_{2}
\end{array}
$$

and

$$
\begin{array}{lll}
E_{1}(z)=E_{1}\left(z_{3}\right)+\tau_{12} \int_{z_{3}}^{z} w_{2} a_{2}(s) d s & \text { for } z_{3}<z \leq z_{5} \\
E_{2}(z)=E_{2}\left(z_{1}\right)+\int_{z_{1}}^{z} w_{2} a_{2}(s) d s & \text { for } z_{1}<z \leq z_{6} \\
E_{3}(z)=E_{3}\left(z_{2}\right)+\tau_{32} \int_{z_{2}}^{z} w_{2} a_{2}(s) d s & \text { for } z_{2}<z \leq z_{4}
\end{array}
$$

Applying Leibniz's rule for differentiation of definite integrals, we derive the following useful relations from (A.2) and (A.3):

$$
\begin{aligned}
& d E_{1}(z)=w_{1} a_{1}(z) d z \quad \text { for } z \leq z_{3} \\
& d E_{2}(z)=\tau_{21} w_{1} a_{1}(z) d z \text { for } z \leq z_{1} \\
& d E_{3}(z)=\tau_{31} w_{1} a_{1}(z) d z \text { for } z \leq z_{2} \\
& d E_{1}(z)=\tau_{12} w_{2} a_{2}(z) d z \text { for } z_{3}<z \leq z_{5} \\
& d E_{2}(z)=w_{2} a_{2}(z) d z \quad \text { for } z_{1}<z \leq z_{6} \\
& d E_{3}(z)=\tau_{32} w_{2} a_{2}(z) d z \text { for } z_{2}<z \leq z_{4}
\end{aligned}
$$


Substituting these relationships into (A.1) we obtain

$$
\begin{aligned}
w_{1} L_{1}= & \int_{0}^{z_{3}} Q_{1}(z) d E_{1}(z)+\int_{0}^{z_{1}} \frac{1}{\tau_{21}} Q_{2}(z) d E_{2}(z)+\int_{0}^{z_{2}} \frac{1}{\tau_{31}} Q_{3}(z) d E_{3}(z) \\
= & \int_{0}^{z_{3}} N_{1}\left[\int_{\frac{E_{1}(z)-T R_{1}}{w_{1}}}^{\infty} d F_{1}\left(h_{1}\right)\right] d E_{1}(z)+\int_{0}^{z_{1}} \frac{N_{2}}{\tau_{21}}\left[\int_{\frac{E_{2}(z)-T R_{2}}{w_{2}}}^{\infty} d F_{2}\left(h_{2}\right)\right] d E_{2}(z) \\
& +\int_{0}^{z_{2}} \frac{N_{3}}{\tau_{31}}\left[\int_{\frac{E_{3}(z)-T R_{3}}{w_{3}}}^{\infty} d F_{3}\left(h_{3}\right)\right] d E_{3}(z) \\
= & N_{1} \int_{0}^{\infty}\left[\int_{0}^{\min \left\{E_{1}^{-1}\left(w_{1} h_{1}+T R_{1}\right), z_{3}\right\}} d E_{1}(z)\right] d F_{1}\left(h_{1}\right) \\
& +\frac{N_{2}}{\tau_{21}} \int_{0}^{\infty}\left[\int_{0}^{\min \left\{E_{2}^{-1}\left(w_{2} h_{2}+T R_{2}\right), z_{1}\right\}} d E_{2}(z)\right] d F_{2}\left(h_{2}\right) \\
& +\frac{N_{3}}{\tau_{31}} \int_{0}^{\infty}\left[\int_{0}^{\min \left\{E_{3}^{-1}\left(w_{3} h_{3}+T R_{3}\right), z_{2}\right\}} d E_{3}(z)\right] d F_{3}\left(h_{3}\right) \\
= & N_{1} \int_{0}^{\infty} \min \left\{w_{1} h_{1}+T R_{1}, E_{1}\left(z_{1}\right)\right\} d F_{1}\left(h_{1}\right) \\
& +\frac{N_{2}}{\tau_{21}} \int_{0}^{\infty} \min \left\{w_{2} h_{2}+T R_{2}, E_{2}\left(z_{1}\right)\right\} d F_{2}\left(h_{2}\right) \\
& +\frac{N_{3}}{\tau_{31}} \int_{0}^{\infty} \min \left\{w_{3} h_{3}+T R_{3}, E_{3}\left(z_{2}\right)\right\} d F_{3}\left(h_{3}\right),
\end{aligned}
$$

where the second equality uses equation (9), the third equality applies a change in variables as in Lederman (1966). Finally, expressing explicitly the inner integrals we obtain:

$$
\begin{aligned}
w_{1} L_{1}= & N_{1} \int_{0}^{\infty} \min \left\{w_{1} h_{1}+T R_{1}, E_{1}\left(z_{1}\right)\right\} d F_{1}\left(h_{1}\right) \\
& +\frac{N_{2}}{\tau_{21}} \int_{0}^{\infty} \min \left\{w_{2} h_{2}+T R_{2}, E_{2}\left(z_{1}\right)\right\} d F_{2}\left(h_{2}\right) \\
& +\frac{N_{3}}{\tau_{31}} \int_{0}^{\infty} \min \left\{w_{3} h_{3}+T R_{3}, E_{3}\left(z_{2}\right)\right\} d F_{3}\left(h_{3}\right) .
\end{aligned}
$$

In a similar way, the labor market conditions for country 2 and 3 can be derived.

\section{A.2 Labor market conditions for countries 2 and 3 and trade balance conditions}

Similar to the derivation of the labor market condition for country 1, we obtain for country 2:

$$
\begin{aligned}
w_{2} L_{2}= & \frac{N_{1}}{\tau_{12}} \int_{0}^{\infty} \min \left[w_{1} h_{1}+T R_{1}-E_{1}\left(z_{3}\right), E_{1}\left(z_{5}\right)-E_{1}\left(z_{3}\right)\right] d F_{1}\left(h_{1}\right) \\
& +N_{2} \int_{0}^{\infty} \min \left[w_{2} h_{2}+T R_{2}-E_{2}\left(z_{1}\right), E_{2}\left(z_{6}\right)-E_{2}\left(z_{1}\right)\right] d F_{2}\left(h_{2}\right) \\
& +\frac{N_{3}}{\tau_{32}} \int_{0}^{\infty} \min \left[w_{3} h_{3}+T R_{3}-E_{3}\left(z_{2}\right), E_{3}\left(z_{4}\right)-E_{3}\left(z_{2}\right)\right] d F_{3}\left(h_{3}\right),
\end{aligned}
$$


where $E_{1}\left(z_{5}\right)-E_{1}\left(z_{3}\right)=\tau_{12} \int_{z_{3}}^{z_{5}} w_{2} a_{2}(s) d s, E_{2}\left(z_{6}\right)-E_{2}\left(z_{1}\right)=\int_{z_{1}}^{z_{6}} w_{2} a_{2}(s) d s$, and $E_{3}\left(z_{4}\right)-$ $E_{3}\left(z_{2}\right)=\tau_{32} \int_{z_{2}}^{z_{4}} w_{2} a_{2}(s) d s$.

For country 3 , we obtain

$$
\begin{aligned}
w_{3} L_{3}= & \frac{N_{1}}{\tau_{13}} \int_{0}^{\infty} \max \left[w_{1} h_{1}+T R_{1}-E_{1}\left(z_{5}\right), 0\right] d F_{1}\left(h_{1}\right) \\
& +\frac{N_{2}}{\tau_{23}} \int_{0}^{\infty} \max \left[w_{2} h_{2}+T R_{2}-E_{2}\left(z_{6}\right), 0\right] d F_{2}\left(h_{2}\right) \\
& +N_{3} \int_{0}^{\infty} \max \left[w_{3} h_{3}+T_{3}-E_{3}\left(z_{4}\right), 0\right] d F_{3}\left(h_{3}\right) .
\end{aligned}
$$

Using Walras' Law we can rearrange equations (A.4)-(A.6) to derive the trade balance conditions for countries 1 and 2 as given in the main text by (12) and (13), respectively.

\section{B Balanced Trade Conditions}

This appendix sketches the derivation of (14) from (12). All other trade balance conditions can be derived in an analogous way. We start from the assumption that, in the symmetric equilibrium, all consumers spend their last unit of income on goods produced in country 3 . Making use of assumption 4 the following inequalities apply:

$$
\begin{aligned}
w_{2}+T R_{2} & >E_{2}\left(z_{1}\right), \\
w_{3}+T R_{3} & >E_{3}\left(z_{2}\right), \\
w_{1}+T R_{1}-E_{1}\left(z_{3}\right) & >E_{1}\left(z_{5}\right)-E_{1}\left(z_{3}\right), \\
w_{1}+T R_{1}-E_{1}\left(z_{5}\right) & >0 .
\end{aligned}
$$

Hence the trade balance condition becomes:

$$
\frac{N_{2}}{\tau_{21}} E_{2}\left(z_{1}\right)+\frac{N_{3}}{\tau_{31}} E_{3}\left(z_{2}\right)=N_{1} \int_{z_{3}}^{z_{5}} w_{2} a_{2}(s) d s+\frac{N_{1}}{\tau_{13}}\left[w_{1} h_{1}+T R_{1}-E_{1}\left(z_{5}\right)\right],
$$

and after making use of country 1's budget constraint yields (14) as given in the main text.

\section{Effects of unilateral tariff reductions}

\section{C.1 Symmetric trade equilibrium}

The symmetric trade equilibrium is contained in the six equations for efficient production (1)-(6), the balanced trade conditions (14), (15), and the budget conditions (16)-(18). Rewriting conditions(1)-(6) in percentage form yields 


$$
\begin{array}{ll}
\widehat{z}_{1}=-\frac{1}{\zeta_{2}}\left[\widehat{\omega}_{2}+\widehat{\tau}_{21}\right], & \widehat{z}_{4}=\frac{1}{\zeta}\left[\widehat{\omega}_{2}-\widehat{\omega}_{3}-\widehat{\tau}_{32}\right], \\
\widehat{z}_{2}=-\frac{1}{\zeta_{2}}\left[\widehat{\tau}_{31}+\widehat{\omega}_{2}-\widehat{\tau}_{32}\right], & \widehat{z}_{5}=\frac{1}{\zeta}\left[\widehat{\omega}_{2}-\widehat{\omega}_{3}+\widehat{\tau}_{13}-\widehat{\tau}_{12}\right], \\
\widehat{z}_{3}=-\frac{1}{\zeta_{2}}\left[\widehat{\omega}_{2}-\widehat{\tau}_{12}\right], & \widehat{z}_{6}=\frac{1}{\zeta}\left[\widehat{\omega}_{2}-\widehat{\omega}_{3}+\widehat{\tau}_{23}\right] .
\end{array}
$$

where $\zeta_{2}>0, \zeta \equiv \zeta_{3}-\zeta_{2}>0$, and where we have applied our assumption that $\zeta_{2}\left(z_{i}\right)=\zeta_{2}$ and $\zeta_{3}\left(z_{i}\right)=\zeta_{3}, \forall i$.

Total differentiation of (14) and (15), making use of (1)-(6) and (16)-(18) and evaluated at $\tau_{i k}=\tau_{i j}$ for $i, j, k=1,2,3$ and $i \neq j, k$ yields

$$
\left[\begin{array}{c}
\widehat{\omega}_{2} \\
\widehat{\omega}_{3}
\end{array}\right]=\frac{1}{D}\left[\begin{array}{cc}
\Omega_{22} & 0 \\
\Omega_{21} & \Omega_{11}
\end{array}\right]\left[\begin{array}{cc}
t_{11} & -t_{21} \\
-t_{12} & t_{22} \\
-t_{13} & t_{23} \\
-t_{14} & t_{24} \\
-t_{15} & t_{25} \\
t_{16} & -t_{26}
\end{array}\right]^{T}\left[\begin{array}{c}
\widehat{\tau}_{12} \\
\widehat{\tau}_{13} \\
\widehat{\tau}_{21} \\
\widehat{\tau}_{23} \\
\widehat{\tau}_{31} \\
\widehat{\tau}_{32}
\end{array}\right],
$$

where the superscript " $T$ " represents the transpose of a vector. The determinant $D=$ $\Omega_{11} \Omega_{22}>0$ since

$$
\begin{aligned}
& \Omega_{11}=N_{1} a_{1}\left(z_{3}\right) z_{3}+N_{2} a_{1}\left(z_{1}\right) z_{1}+N_{3} a_{1}\left(z_{2}\right) z_{2}>0, \\
& \Omega_{21}=\Omega_{22}+\zeta\left[N_{1} a_{2}\left(z_{3}\right) z_{3}+N_{2} a_{2}\left(z_{1}\right) z_{1}+N_{3} a_{2}\left(z_{2}\right) z_{2}\right]>0, \\
& \Omega_{22}=\zeta_{2}\left[N_{1} a_{2}\left(z_{5}\right) z_{5}+N_{2} a_{2}\left(z_{6}\right) z_{6}+N_{3} a_{2}\left(z_{4}\right) z_{4}\right]>0 .
\end{aligned}
$$

With

$$
\begin{aligned}
t_{11}=N_{1} a_{1}\left(z_{3}\right) z_{3}, & t_{12}=0, \\
t_{13}=N_{2} a_{1}\left(z_{1}\right) z_{1}, & t_{14}=0, \\
t_{15}=N_{3} a_{1}\left(z_{2}\right) z_{2}, & t_{16}=N_{3} a_{1}\left(z_{2}\right) z_{2}, \\
t_{21}=N_{1}\left[\zeta_{2} a_{2}\left(z_{5}\right) z_{5}+\zeta a_{2}\left(z_{3}\right) z_{3}\right], & t_{22}=\zeta_{2} N_{1} a_{2}\left(z_{5}\right) z_{5}, \\
t_{23}=\zeta N_{2} a_{2}\left(z_{1}\right) z_{1}, & t_{24}=\zeta_{2} N_{2} a_{2}\left(z_{6}\right) z_{6}, \\
t_{25}=\zeta N_{3} a_{2}\left(z_{2}\right) z_{2}, & t_{26}=N_{3}\left[\zeta_{2} a_{2}\left(z_{4}\right) z_{4}+\zeta a_{2}\left(z_{2}\right) z_{2}\right] .
\end{aligned}
$$

It is helpful to recognize that

$$
\begin{aligned}
\Omega_{22}-\Omega_{21} & =-\zeta\left[N_{1} a_{2}\left(z_{3}\right) z_{3}+N_{2} a_{2}\left(z_{1}\right) z_{1}+N_{3} a_{2}\left(z_{2}\right) z_{2}\right]<0, \\
& =-\zeta \omega_{2}\left[N_{1} a_{1}\left(z_{3}\right) z_{3} / \tau_{12}+N_{2} a_{1}\left(z_{1}\right) z_{1} \tau_{21}+N_{3} a_{1}\left(z_{2}\right) z_{2}\right]<0, \\
\Omega_{21}-\Omega_{11} \zeta \omega_{2} & =\Omega_{22}+\zeta \omega_{2}\left[N_{1} a_{1}\left(z_{3}\right) z_{3}\left(\frac{1}{\tau_{12}}-1\right)+N_{2} a_{1}\left(z_{1}\right) z_{1}\left(\tau_{21}-1\right)\right], \\
& =\Omega_{22}+\zeta\left[N_{1} a_{2}\left(z_{3}\right) z_{3}\left(1-\tau_{12}\right)+N_{2} a_{1}\left(z_{1}\right) z_{1} \omega_{2}\left(\tau_{21}-1\right)\right], \\
\Omega_{21}-\Omega_{11} \zeta \omega_{2} / \tau_{12} & =\Omega_{22}+\zeta \omega_{2}\left[N_{2} a_{1}\left(z_{1}\right) z_{1}\left(\tau_{21}-\frac{1}{\tau_{12}}\right)+N_{3} a_{1}\left(z_{2}\right) z_{2}\left(1-\frac{1}{\tau_{12}}\right)\right]>0, \\
\Omega_{21}-\Omega_{11} \zeta \omega_{2} \tau_{21} & =\Omega_{22}-\zeta \omega_{2}\left[N_{1} a_{1}\left(z_{3}\right) z_{3}\left(\tau_{21}-\frac{1}{\tau_{12}}\right)+N_{3} a_{1}\left(z_{2}\right) z_{2}\left(\tau_{21}-1\right)\right],
\end{aligned}
$$


where we make use of (1)-(6) and the assumption that $\tau_{i k}=\tau_{i j}$ for $i, j, k=1,2,3$ and $i \neq j$, $k$. Now, substituting the elements $t_{i j}$ into (C.2) and (C.1) makes it possible to derive the results shown in Table 1 of the text. The comparable results obtained by ACF are given in the same table by the panel on the right. These results coincide with those as given in Table 1, p. 154 of ACF.

\section{C.2 Asymmetric trade equilibrium}

The asymmetric trade equilibrium is contained in the six equations for efficient production (1)-(6), the balanced trade conditions (19) and (20), and the budget conditions (21), (17), and (18). The percentage change in relative wages can then be deduced from the following system:

$$
\left[\begin{array}{c}
\widehat{\omega}_{2} \\
\widehat{\omega}_{3}
\end{array}\right]=\frac{1}{\widetilde{D}}\left[\begin{array}{cc}
\widetilde{\Omega}_{22} & 0 \\
\widetilde{\Omega}_{21} & \widetilde{\Omega}_{11}
\end{array}\right]\left[\begin{array}{cc}
s_{11} & -s_{21} \\
-s_{13} & s_{23} \\
s_{14} & s_{24} \\
-s_{15} & s_{25} \\
s_{16} & -s_{26}
\end{array}\right]^{T}\left[\begin{array}{c}
\widehat{\tau}_{12} \\
\widehat{\tau}_{21} \\
\widehat{\tau}_{23} \\
\widehat{\tau}_{31} \\
\widehat{\tau}_{32}
\end{array}\right]
$$

with $\widetilde{D}=\widetilde{\Omega}_{22} \widetilde{\Omega}_{11}>0$ and

$$
\begin{aligned}
\widetilde{\Omega}_{11}= & N_{1} a_{1}\left(z_{3}\right) z_{3}+N_{2} a_{1}\left(z_{1}\right) z_{1}+N_{3} a_{1}\left(z_{2}\right) z_{2}>0, \\
\widetilde{\Omega}_{22}= & \zeta_{2}\left[N_{2} a_{2}\left(z_{6}\right) z_{6}+N_{3} a_{2}\left(z_{4}\right) z_{4}\right]>0, \\
\widetilde{\Omega}_{21}= & \zeta \omega_{2} N_{1}\left[\zeta_{2}\left(1-\int_{0}^{z_{3}} a_{1}(s) d s\right)+a_{1}\left(z_{3}\right) z_{3}\right] \\
& +N_{2}\left[\zeta a_{2}\left(z_{1}\right) z_{1}+\zeta_{2} a_{2}\left(z_{6}\right) z_{6}\right]+N_{3}\left[\zeta a_{2}\left(z_{2}\right) z_{2}+\zeta_{2} a_{2}\left(z_{4}\right) z_{4}\right]>0 .
\end{aligned}
$$

With

$$
\begin{aligned}
s_{11}=N_{1} a_{1}\left(z_{3}\right) z_{3} & s_{12}=0, \\
s_{13}=N_{2} a_{1}\left(z_{1}\right) z_{1}, & s_{14}=0, \\
s_{15}=N_{3} a_{1}\left(z_{2}\right) z_{2}, & s_{16}=N_{3} a_{1}\left(z_{2}\right) z_{2}>0, \\
s_{21}=\zeta N_{1} \omega_{2} a_{1}\left(z_{3}\right) z_{3}, & s_{22}=0, \\
s_{23}=\zeta N_{2} a_{2}\left(z_{1}\right) z_{1}, & s_{24}=\zeta_{2} N_{2} a_{2}\left(z_{6}\right) z_{6}, \\
s_{25}=\zeta N_{3} a_{2}\left(z_{2}\right) z_{2}, & s_{26}=N_{3}\left[\zeta_{2} a_{2}\left(z_{4}\right) z_{4}+\zeta a_{2}\left(z_{2}\right) z_{2}\right] .
\end{aligned}
$$


It is helpful to recognize that

$$
\begin{aligned}
\widetilde{\Omega}_{21} & =\widetilde{\Omega}_{22}+\zeta \omega_{2} N_{1}\left[\zeta_{2}\left(1-\int_{0}^{z_{3}} a_{1}(s) d s\right)+a_{1}\left(z_{3}\right) z_{3}\right] \\
& +\zeta\left[N_{2} a_{2}\left(z_{1}\right) z_{1}+N_{3} a_{2}\left(z_{2}\right) z_{2}\right]>0, \\
\widetilde{\Omega}_{21}-\zeta \omega_{2} \widetilde{\Omega}_{11} & =\widetilde{\Omega}_{22}+\zeta \omega_{2}\left[\zeta_{2} N_{1}\left(1-\int_{0}^{z_{3}} a_{1}(s) d s\right)+N_{2} a_{1}\left(z_{1}\right) z_{1}\left(\tau_{21}-1\right)\right]>0, \\
\widetilde{\Omega}_{21}-\tau_{21} \zeta \omega_{2} \widetilde{\Omega}_{11} & =\widetilde{\Omega}_{22}+\zeta \omega_{2}\left[\zeta_{2} N_{1}\left(1-\int_{0}^{z_{3}} a_{1}(s) d s\right)-\left(N_{1} a_{1}\left(z_{3}\right) z_{3}+N_{3} a_{1}\left(z_{2}\right) z_{2}\right)\left(\tau_{21}-1\right)\right] .
\end{aligned}
$$

Substituting the elements $s_{i j}$ into (C.3) makes it possible to derive the results shown in

Table 1b. This also determines the signs of $\widehat{\omega_{2} / \omega_{3}}$. The signs for $\widehat{z}_{i}, i=1 . .6$, follow by applying (C.1).This leads to the comparative statics results for unilateral tariff reductions as given in Table $1 b$ in the main text (left panel).

\section{Welfare expressions}

In this part of the appendix we derive the welfare expressions used to derive the results illustrated in Tables 5, 6a,b, and 7a,b. The welfare effects follow from total differentiation of equations (16)-(18) for the symmetric trade equilibrium and equations (17)-(18) plus (21) for the asymmetric trade equilibrium and making use of the assumption that each country imposes the same tariff rate on its imports regardless of the country of origin, i.e., $\tau_{j k}=\tau_{j k^{\prime}}$ for $j, k, k^{\prime}=1,2,3$. We confine the discussion to the welfare effects for the symmetric trade equilibrium and for country 1 . Those for the other countries and the asymmetric trade equilibrium follow by applying analogous methodology. For country 1, we calculate

$$
\begin{aligned}
a_{3}\left(u_{1}\right) d u_{1}= & a_{3}\left(z_{5}\right) z_{5} \widehat{z}_{5}-\omega_{3} a_{1}\left(z_{3}\right) z_{3} \widehat{z}_{3}-\frac{\omega_{3}}{\omega_{2}}\left[a_{2}\left(z_{5}\right) z_{5} \widehat{z}_{5}-a_{2}\left(z_{3}\right) z_{3} \widehat{z}_{3}\right] \\
& +\frac{\omega_{3}}{\omega_{2}} \int_{z_{3}}^{z_{5}} a_{2}(s) d s \widehat{\omega}_{2}+\int_{z_{5}}^{u_{1}} a_{3}(s) d s \widehat{\omega}_{3} .
\end{aligned}
$$

When we use (1)-(6), the expression can be rewritten to

$$
\begin{aligned}
a_{3}\left(u_{1}\right) d u_{1}= & \left(1-\frac{\tau_{13}}{\tau_{12}}\right) a_{3}\left(z_{5}\right) z_{5} \widehat{z}_{5}+\left(1-\tau_{12}\right) \frac{\omega_{3}}{\omega_{2}} a_{2}\left(z_{3}\right) z_{3} \widehat{z}_{3} \\
& +\frac{\omega_{3}}{\omega_{2}} \int_{z_{3}}^{z_{5}} a_{2}(s) d s \widehat{\omega}_{2}+\int_{z_{5}}^{u_{1}} a_{3}(s) d s \widehat{\omega}_{3}
\end{aligned}
$$

so that when $\tau_{12}=\tau_{13}$ it reduces to the expression as given in the main text. 


\section{Tables and Figures}

Table 1a: Effects of unilateral tariff changes, symmetric trade equilibrium

\begin{tabular}{|c|c|c|c|c|c|c|}
\hline \multirow[t]{2}{*}{ Our analysis } & \multicolumn{6}{|c|}{$\mathrm{A}$ rise in : } \\
\hline & $\tau_{12}$ & $\tau_{13}$ & $\tau_{21}$ & $\tau_{23}$ & $\tau_{31}$ & $\tau_{32}$ \\
\hline$z_{1}$ & - & 0 & - & 0 & + & - \\
\hline$z_{2}$ & - & 0 & + & 0 & - & + \\
\hline$z_{3}$ & + & 0 & + & 0 & + & - \\
\hline$z_{4}$ & $-{ }^{1} /+^{2}$ & - & - & - & $-{ }^{4}$ & $+^{3} /-^{2}$ \\
\hline$z_{5}$ & - & + & - & - & -4 & $+^{3} /+^{2}$ \\
\hline$z_{6}$ & $-{ }^{1} /+^{2}$ & - & - & + & $-{ }^{4}$ & $+^{3} /+^{2}$ \\
\hline$\omega_{2}$ & + & 0 & - & 0 & - & + \\
\hline$\omega_{3}$ & $+^{1} / ?^{2}$ & + & $+{ }^{1} /-^{2}$ & + & $++^{3} /-^{2}$ & $-3 / ?$ \\
\hline$\omega_{2} / \omega_{3}$ & $-{ }^{1} /+^{2}$ & - & - & - & $-{ }^{4}$ & $+^{3} /+^{2}$ \\
\hline & \multicolumn{6}{|c|}{$\begin{array}{l}{ }^{1} \text { if } \zeta_{2} \rightarrow 0 ; \quad{ }^{2} \text { if } \zeta \rightarrow 0 ; \\
{ }^{3} \text { if } \zeta_{2} \rightarrow 0 \text { and } N_{1} a_{1}\left(z_{3}\right) z_{3}\left(1-\frac{1}{\tau_{12}}\right)>N_{2} a_{1}\left(z_{1}\right) z_{1}\left(\tau_{21}-1\right) ; \\
{ }^{4} \text { if } N_{1} a_{1}\left(z_{3}\right) z_{3}\left(1-\frac{1}{\tau_{12}}\right)>N_{2} a_{1}\left(z_{1}\right) z_{1}\left(\tau_{21}-1\right) ;\end{array}$} \\
\hline
\end{tabular}

\begin{tabular}{|c|c|c|c|c|c|c|}
\hline \multirow[t]{2}{*}{$A C F$} & \multicolumn{6}{|c|}{ A rise in: } \\
\hline & $\tau_{12}$ & $\tau_{13}$ & $\tau_{21}$ & $\tau_{23}$ & $\tau_{31}$ & $\tau_{32}$ \\
\hline$z_{1}$ & - & + & - & + & + & - \\
\hline$z_{2}$ & - & + & + & + & - & + \\
\hline$z_{3}$ & + & + & + & + & + & - \\
\hline$z_{4}$ & + & - & - & - & - & - \\
\hline$z_{5}$ & - & + & - & - & - & + \\
\hline$z_{6}$ & + & - & - & + & - & + \\
\hline$\omega_{2}$ & + & - & - & - & - & + \\
\hline$\omega_{3}$ & \pm & + & - & + & - & \pm \\
\hline$\omega_{2} / \omega_{3}$ & + & - & - & - & - & + \\
\hline
\end{tabular}


Table 1b: Effects of unilateral tariff changes, asymmetric trade equilibrium

\begin{tabular}{||cccccc||}
\hline \hline Our analysis & \multicolumn{1}{l||}{ A rise in: } \\
\hline \multicolumn{7}{c}{$\tau_{12}$} & $\tau_{21}$ & $\tau_{23}$ & $\tau_{31}$ & $\tau_{32}$ \\
$z_{1}$ & - & - & 0 & + & - \\
$z_{2}$ & - & + & 0 & - & + \\
$z_{3}$ & + & + & 0 & + & - \\
$z_{4}$ & - & $-{ }^{1}$ & - & + & - \\
$z_{6}$ & - & $-{ }^{1}$ & + & + & $-{ }^{1} /+^{2}$ \\
$\omega_{2}$ & + & - & 0 & - & + \\
$\omega_{3}$ & + & $+{ }^{1} /-^{2}$ & + & - & $+{ }^{1} / ?^{2}$ \\
$\omega_{2} / \omega_{3}$ & - & $-{ }^{1} / ?^{2}$ & - & + & $-{ }^{1} /+^{2}$ \\
\hline \hline \multicolumn{7}{|c}{} & ${ }^{1}$ if $\zeta_{2} \rightarrow 0 ;$ & ${ }^{2}$ if $\zeta \rightarrow 0 ;$ & \\
\hline \hline
\end{tabular}

The results obtained by ACF are taken from Table 1, p. 154 of ACF (1989). The comparison with $\mathrm{ACF}$ is not relevant for the asymmetric case, as in their framework spending is symmetric by definition. 


\section{General equilibrium effects of PTAs}

\begin{tabular}{||c|c|c|c|c|c|c|c|c|c||}
\hline \hline Table 2: General equilibrium results for $\mathbf{P T A}_{23}$ : \\
\hline \hline & \multicolumn{7}{|c||}{ A mutual decline in tariffs gives rise to: } \\
\cline { 2 - 9 } & $z_{1}$ & $z_{2}$ & $z_{3}$ & $z_{4}$ & $z_{5}$ & $z_{6}$ & $\omega_{2}$ & $\omega_{3}$ & $\omega_{2} / \omega_{3}$ \\
\hline symmetric equilibrium: & + & - & + & $-{ }^{4} /+^{2}$ & $-{ }^{4} /+^{3}$ & $-{ }^{4} /-^{2}$ & - & $+{ }^{4} /{ }^{3}$ & $-{ }^{4} /+^{3}$ \\
\hline asymmetric equilibrium: & + & - & + & $+^{1} /+^{2}$ & n.a. & $+{ }^{1} /-^{2}$ & - & $-{ }^{1} /-^{3}$ & $+^{1} /+^{3}$ \\
\hline & ${ }^{1}$ if $\zeta_{2} \rightarrow 0 ;{ }^{2}$ if $\zeta \rightarrow 0 ;$ \\
& ${ }^{3}$ if $\zeta \rightarrow 0$ and $N_{2} a_{2}\left(z_{6}\right) z_{6}>N_{3} a_{2}\left(z_{4}\right) z_{4} ;$ \\
& ${ }^{4}$ if $\zeta_{2} \rightarrow 0$ and $N_{1} a_{1}\left(z_{3}\right) z_{3}\left(1-\frac{1}{\tau_{12}}\right)>N_{2} a_{1}\left(z_{1}\right) z_{1}\left(\tau_{21}-1\right) ;$ \\
\hline \hline
\end{tabular}

Table 3: General equilibrium results for PTA $_{12}$ :

\begin{tabular}{|c|c|c|c|c|c|c|c|c|c|}
\hline & \multicolumn{9}{|c|}{ A mutual decline in tariffs gives rise to: } \\
\hline & $z_{1}$ & $z_{2}$ & $z_{3}$ & $z_{4}$ & $z_{5}$ & $z_{6}$ & $\omega_{2}$ & $\omega_{3}$ & $\omega_{2} / \omega_{3}$ \\
\hline \multirow{3}{*}{$\begin{array}{l}\text { symmetric equilibrium: } \\
\text { asymmetric equilibrium: }\end{array}$} & + & $++^{4}$ & - & $++^{1} /-^{2}$ & + & $++^{1} /-^{2}$ & $-{ }^{4}$ & $-{ }^{1} / ?^{2}$ & $++^{1} /-^{2}$ \\
\hline & + & $+^{4}$ & - & $+^{1} / ?^{2}$ & n.a. & $+^{1} / ?^{2}$ & -4 & $-{ }^{1} /-^{3}$ & $+^{1} / ?^{2}$ \\
\hline & \multicolumn{9}{|c|}{$\begin{array}{l}{ }^{1} \text { if } \zeta_{2} \rightarrow 0 ;{ }^{2} \text { if } \zeta \rightarrow 0 \\
{ }^{3} \text { if } \zeta \rightarrow 0 \text { and } N_{1} a_{1}\left(z_{3}\right) z_{3}>N_{2} a_{1}\left(z_{1}\right) z_{1} \\
{ }^{4} \text { if } N_{1} a_{1}\left(z_{3}\right) z_{3}>N_{2} a_{1}\left(z_{1}\right) z_{1}\end{array}$} \\
\hline
\end{tabular}

\section{Table 4: General equilibrium results for $\mathrm{PTA}_{13}$}

\begin{tabular}{|c|c|c|c|c|c|c|c|c|c|}
\hline & \multicolumn{9}{|c|}{ A mutual decline in tariffs gives rise to: } \\
\hline & $z_{1}$ & $z_{2}$ & $z_{3}$ & $z_{4}$ & $z_{5}$ & $z_{6}$ & $\omega_{2}$ & $\omega_{3}$ & $\omega_{2} / \omega_{3}$ \\
\hline \multirow{3}{*}{$\begin{array}{l}\text { symmetric equilibrium: } \\
\text { asymmetric equilibrium: }\end{array}$} & - & + & - & $+^{3} /+^{2}$ & $++^{3} /-^{2}$ & $++^{3} /+^{2}$ & + & $-{ }^{3}$ & $++^{3} /+^{2}$ \\
\hline & - & + & - & - & n.a. & - & + & + & - \\
\hline & \multicolumn{9}{|c|}{$\begin{array}{l}{ }^{1} \text { if } \zeta_{2} \rightarrow 0 ; \quad{ }^{2} \text { if } \zeta \rightarrow 0 ; \\
{ }^{3} \text { if } \zeta_{2} \rightarrow 0 \text { and } N_{1} a_{1}\left(z_{3}\right) z_{3}\left(1-\frac{1}{\tau_{12}}\right)>N_{2} a_{1}\left(z_{1}\right) z_{1}\left(\tau_{21}-1\right) ;\end{array}$} \\
\hline
\end{tabular}




\section{Welfare effects of PTAs}

Table 5: Welfare effects of PTAs for uniform tariff structures

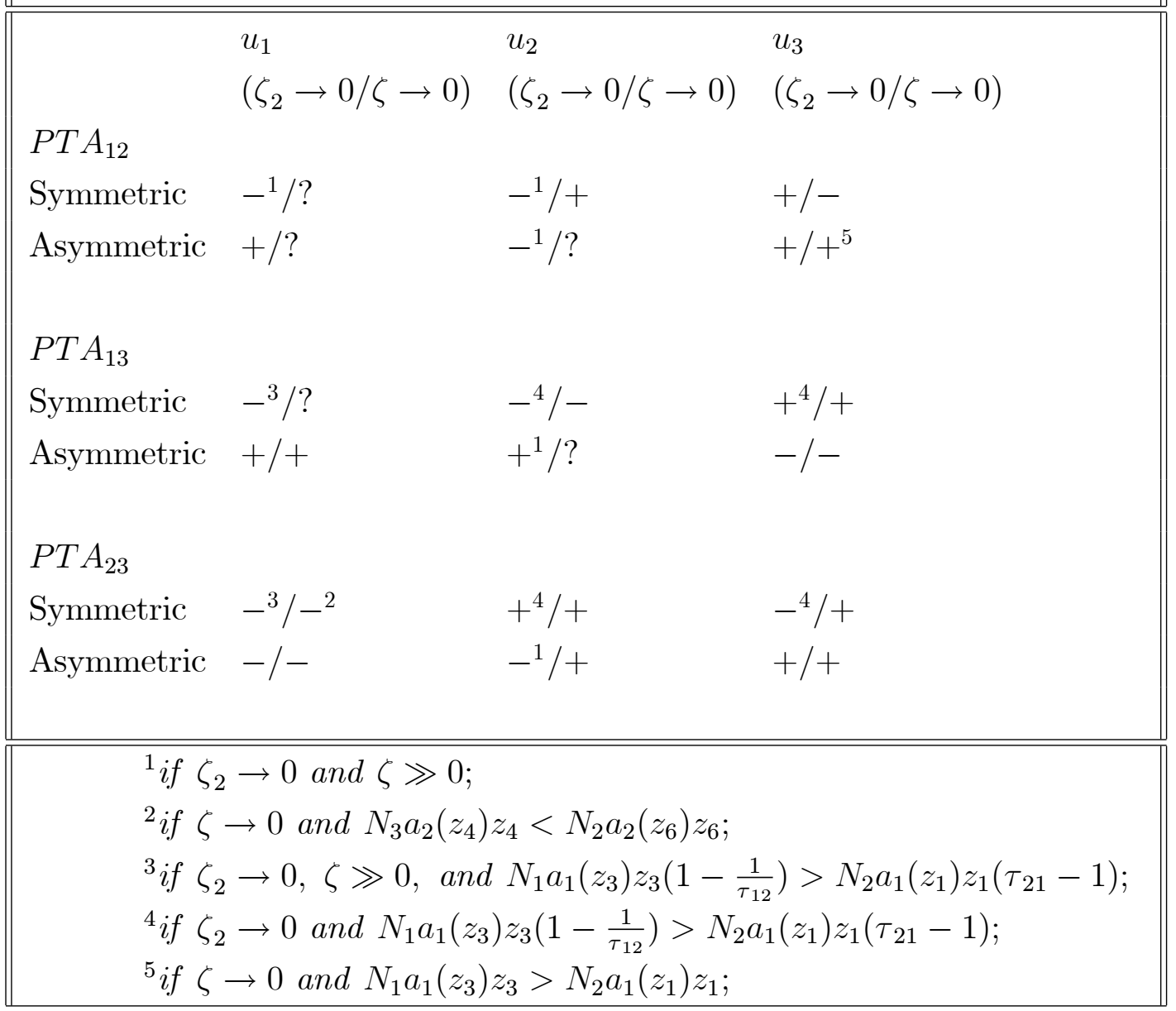




\section{Welfare effects of unilateral tariff changes}

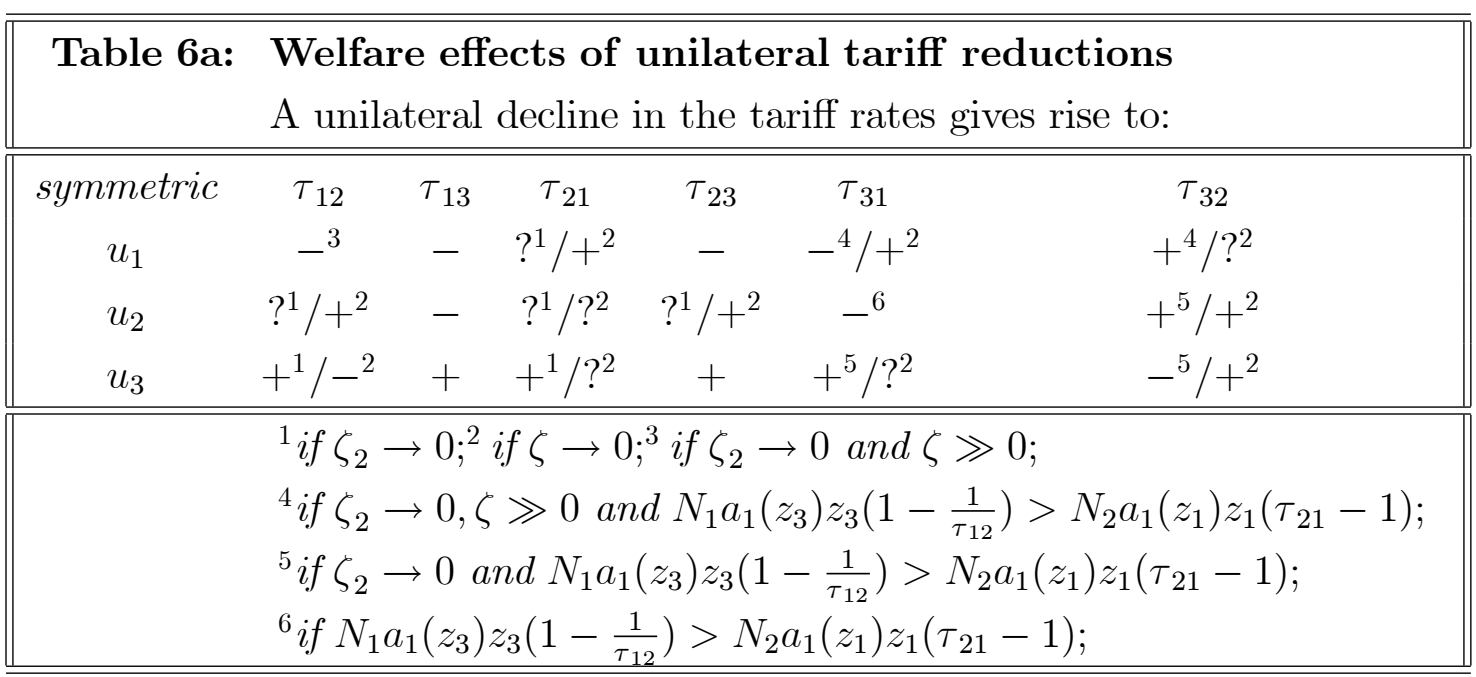

Table 6b: Welfare effects of unilateral tariff reductions

A unilateral decline in the tariff rates gives rise to:

\begin{tabular}{||cccccc||}
\hline asymmetric & $\tau_{12}$ & $\tau_{21}$ & $\tau_{23}$ & $\tau_{31}$ & $\tau_{32}$ \\
\hline \hline$u_{1}$ & $+{ }^{1} / ?^{2}$ & + & 0 & + & - \\
$u_{2}$ & $-{ }^{3} / ?^{2}$ & $-{ }^{3} / ?^{2}$ & $+^{2}$ & $+^{3} / ?^{2}$ & $-{ }^{3} /+^{2}$ \\
$u_{3}$ & $+{ }^{1} /+^{2}$ & $+{ }^{1} / ?^{2}$ & + & $-{ }^{1} /-^{2}$ & $+{ }^{1} /+^{2}$ \\
\hline \hline & ${ }^{1}$ if $\zeta_{2} \rightarrow 0 ;$ \\
& ${ }^{2}$ if $\zeta \rightarrow 0 ;$ \\
& ${ }^{3}$ if $\zeta_{2} \rightarrow 0$ and $\zeta \gg 0 ;$ \\
\hline \hline
\end{tabular}




\section{Multilateral tariff reductions}

\section{Table 7a: General equilibrium results for multilateral tariff reductions}

\begin{tabular}{||r|c|c|c|c|c|c|c|c|c||}
\hline \hline & \multicolumn{7}{|c||}{ A mutual decline in tariffs gives rise to: } \\
\cline { 2 - 8 } & $z_{1}$ & $z_{2}$ & $z_{3}$ & $z_{4}$ & $z_{5}$ & $z_{6}$ & $\omega_{2}$ & $\omega_{3}$ & $\omega_{2} / \omega_{3}$ \\
\hline symmetric equilibrium: & + & $+^{3}$ & - & + & $+{ }^{1} /+^{4}$ & $+{ }^{1} /-^{2}$ & $-{ }^{3}$ & $-{ }^{1} / ?^{2}$ & $+{ }^{1} /+^{4}$ \\
asymmetric equilibrium: & + & $+^{3}$ & - & $+{ }^{1} /+^{2}$ & n.a. & $+{ }^{1} /-^{2}$ & $-{ }^{3}$ & $-{ }^{1} / ?^{2}$ & $+{ }^{1} /+^{4}$ \\
\hline & ${ }^{1}$ if $\zeta_{2} \rightarrow 0 ;$ & ${ }^{2}$ if $\zeta \rightarrow 0 ;$ \\
& ${ }^{3}$ if $N_{1} a_{1}\left(z_{3}\right) z_{3}>N_{2} a_{2}\left(z_{1}\right) z_{1} ;$ \\
& ${ }^{4}$ if $\zeta \rightarrow 0$ and $N_{2} a_{2}\left(z_{6}\right) z_{6}>N_{3} a_{2}\left(z_{4}\right) z_{4} ;$ \\
\hline \hline
\end{tabular}

Table 7b: Welfare effects of multilateral tariff reductions

A mutual decline in all tariff rates gives rise to:

\begin{tabular}{||c||c||c||}
\hline \hline & $\tau_{\text {symmetric }}$ & $\tau_{\text {asymmetric }}$ \\
$u_{1}$ & $-{ }^{3} / ?^{2}$ & $+^{1}$ \\
$u_{2}$ & $-{ }^{3} /+^{2}$ & $-{ }^{3} /+^{2}$ \\
$u_{3}$ & $+{ }^{1} /+^{2}$ & $+{ }^{1} /+^{2}$ \\
& & \\
\hline \hline
\end{tabular}


Figure 1: Production and trade patterns

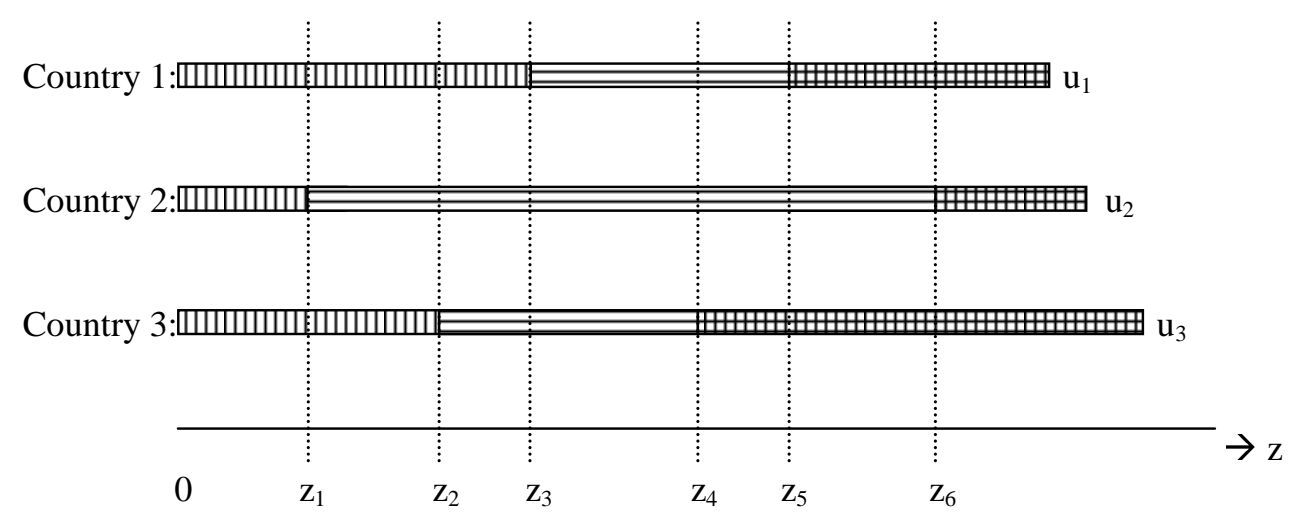

एس山سm Country 1 production

Country 2 production

巴m㘞囘 Country 3 production

NT: non-traded goods 